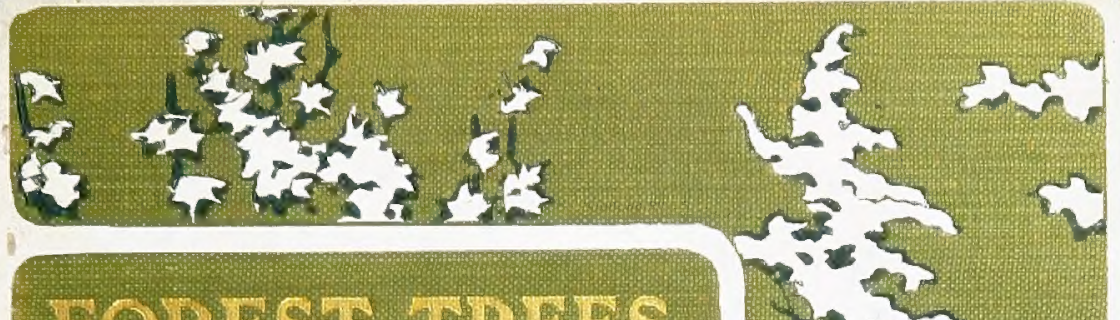

FOREST TREES

AND FOREST

SCENERY

G. FRDDDRICK SOHWARZ 


\section{CORNELL \\ UNIVERSITY \\ LIBRARY}

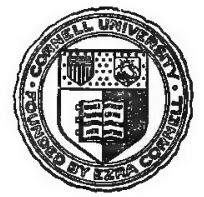




\section{Cornell Unlversity Library}

SD 373.S41 1902

Forest trees and forest scenery,

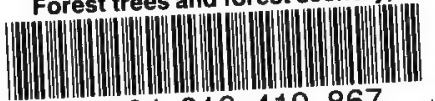

$31924016419867 \quad$ olin, anx 


\section{Cornell University Library}

The original of this book is in the Cornell University Library.

There are no known copyright restrictions in the United States on the use of the text. 




\section{FOREST TREES AND FOREST SCENERY}








A River Scene in Florida 


\title{
FOREST TREES AND FOREST SCENERY
}

\author{
BY \\ G. FREDERICK SCHWARZ
}

ILLUSTRATED

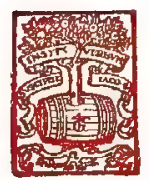

NEW YORK

THE GRAFTON PRESS

1902 
Copyright, 1802, by

G. Freprriok BoHwarz 


\section{PREFACE}

IN the ensuing pages I have made simple inquiries into the sources of beauty and attractiveness in American forest trees and sylvan scenery. In the concluding chapter, by way of contrast, I have given a short account of the esthetic effects of the artificial forests of Europe. The system which shaped these forests and gave them their present appearance should, however, possess more than a comparative interest for Americans. It has, in fact, a further connection, though a slight one, with the subject, and therefore requires a few words of explanation.

It is well known that in many parts of Europe the forests have long been subjected to a systematic treatment known as forestry. The term, at first strange, is gradually becoming quite familiar to us Americans, for the application of this comparatively new science has already begun in many sections 
of our country. The principles of European forestry will naturally undergo many modifications in their new environment, and the vastness of our forest areas, as well as the long life that naturally belongs to trees, will impose a very gradual progress. Nevertheless, the movement for a rational use of our forests is rapidly advancing and is certain in time to find a very wide application.

Although the aims of forestry are utilitarian and not artistic, the technical character of the operations which it involves impresses upon natural forest scenery a changed aspect. Eventually the work performed upon our forests will be manifested in a new outward appearance, a change that cannot but be preferable to the scenes ordinarily presented by our cut-over and abandoned timberlands, and one that will be appreciated not only by forest lovers in general, but also by those who are engaged in the lumber industry itself, who are often forced through competition and prevailing methods to leave a desolate picture behind. 
In a word, forestry interests us here because, having already obtained a foothold in our country, through it forest beauty stands on the threshold of a new relationship. This relationship, which is to grow more intimate with time, appears to justify a certain discrimination in the choice of the trees and forests herein deseribed, and an occasional reference to some of the less technical matters of forestry that may incidentally suggest themselves as being of some interest to the general reader. To have attempted more than this would have detracted from the unity of the subject. While the reader may, therefore, find in these pages some facts that are new to him, he will notice that these facts have been made subordinate to the leading object of the book, an appreciation of the esthetic value of some of our commonest forest trees.

The illustrations have been derived from various sources. The plates facing pages 38 , $58,62,64,66,116,120,130$, are reproductions from original photographs that were furnished 
through the courtesy of the Bureau of Forestry, United States Department of Agriculture. My grateful acknowledgments are due Mr. Overton W. Price, Assistant Chief of the Bureau of Forestry, for photographs chosen out of his collection to supply the plates facing pages $69,148,158$. The remaining illustrations have been reproduced from photographs in my own collection.

Notes of reference, which are indicated by superior figures in the text, and an index to the names of the trees that have been described or specially referred to in these pages, will be found at the close of the book. The index has been compiled from a well-known bulletin of the Bureau of Forestry, United States Department of Agriculture, entitled "Check List of the Forest Trees of the United States." Courteous acknowledgment is here made to the author, Mr. George B. Sudworth, and to the Division of Publications, of the same Department, for kind permission to make extracts from the balletin referred to. viii 


\section{CONTENTS}

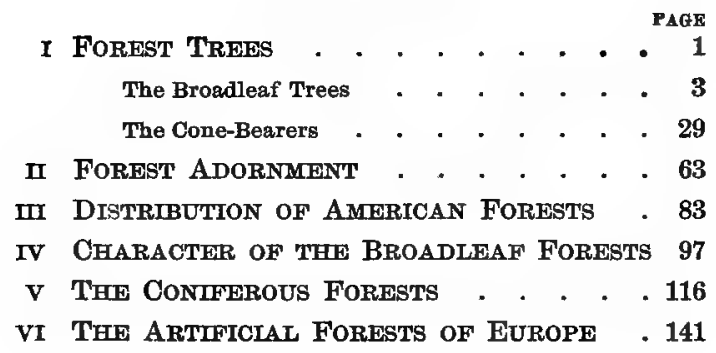





\section{LIST OF ILLUSTRATIONS}

A River Scene in Florida . . . Frontispiece Facing page

Foliage of the White Oak . . . . . . 8

Spray of the Sugar Maple . . . . . . 12

Spray of the Red Maple . . . . . . . 12

The Dogwood in Bloom . . . . . . . 22

Tulip Trees . • . • • • • • • • • 26

Character of the White Pine . . . . . 34

Sugar Pines . . . . . . . . • • • 36

A Pinery in the South . . . . . . . . 38

The Bull Pine in its California Home . . . 40

A Silver Fir at Middle Age . . . . . . . 50

Redwood Forest in California . . . . . . 58

Devastation in the Forest . . . . . . 60

Where the Sheep Have Been . . . . . . 62

A Passageway through Granite Rocks . . . 64

Shrubbery and River Birches. New Jersey . 66

Fern Patch in a Grove of White Birch . . . 69

A Yucca in the Chaparral . . . . . . . 78 


\section{LIST OF ILLUSTRATIONS}

Virgin Forest Scene in Florida . . . . 110

A Group of Conifers. Montana . . . . . 116

Mount Rainier. Washington . . . . . 120

A Thicket of White Firs . . . . . . . . 125

An Open Forest in the Southwest. . . . 130

A Storm-beaten Veteran . . . . . . 132

A German "Selection Forest". . . . . . 148

A "High Forest" of Spruce in Saxony . . . 158 


\section{FOREST TREES AND FOREST SCENERY}


"One impulse from a vernal wood May teach you more of man, Of moral evil and of good, Than all the sages can."

WORDSWORTH. 


\section{I}

\section{FOREST TREES}

THE beauty of a forest is not simple

1 in character, but is due to many separate sources. The trees contribute much; the shrubs, the rocks, the mosses, play their part; the purity of the air, the forest silence, the music of wind in the trees - these and other influences combine to produce woodland beauty and charm. A first consideration, however, should be to know the beauty that is revealed by the trees themselves.

Here it will be wise to make a selection: to choose out of the great variety of our forest flora those trees that most 
deserve our attention. Many of our forest trees have naturally a restricted range; others are narrowing or widening their range through human interference; still others have already established their right to a preëminence among the trees of the future, because, possessing to an unusual degree the qualities that will make them amenable to the new and improved methods of treatment known as "forestry," they are certain to receive special care and attention; while those that are not so fortunate will be left to fight their own battles, or may even be exterminated to make room for the more useful kinds. Among all these the rarest are not necessarily the most beautiful. Those that are commonest and most useful are often distinguished for qual- 
ities that please the eye or appeal directly to the mind.

In accordance with the ideas already expressed in the Preface, the considerations that will determine what trees shall be described are as follows : first, trees of beauty; next, those that are common and familiar; finally, those that are important both for the present and the future because they are useful and have an extended geographical distribution.

The trees selected for description will here be divided into the two conventional groups of broadleaf species and conifers, beginning with the former.

THE BROADLEAF TREES

In the "Landscape Gardening" of Downing we read concerning the oak, - 
FOREST TREES AND FOREST SCENERY

"When we consider its great and surpassing utility and beauty, we are fully disposed to concede it the first rank among the denizens of the forest. Springing up with a noble trunk, and stretching out its broad limbs over the soil,

'These monarchs of the wood, Dark, gnarled, centennial oaks,'

seem proudly to bid defiance to time; and while generations of man appear and disappear, they withstand the storms of a thousand winters, and seem only to grow more venerable and majestic."

It would be difficult to say whether Downing had any particular species of oak in mind when he wrote these words. The common white oak and the several species of red and black oak possess in 
an eminent degree the grandeur and strength which he describes and for which we commonly admire the tree.

Of all the oaks ${ }^{1}$ the white oak is the most important. This tree will impress us differently as we see it in the open field or in the dense forest. Where it stands by itself in the full enjoyment of light, it has a roundtopped, dome-shaped crown, and is massive and well poised in all its parts. Quite as often, however, we shall see it gathered into little groups of three or four on the greensward of some gently sloping hill, where it has a graceful way of keeping company. The groups are full of expression, the effect is diversified from tree to tree, yet harmonious in the whole. In the denser forest the white oak often reaches noble pro- 
portions and assumes its most individual expression. There it mounts proudly upward, contending in height at wide intervals with sugar maples and tulip trees, its common associates in the forest. Its lofty crown may be seen at a distance, lifted conspicuously above the heads of its neighbors. Stand beneath it, however, and look up at its lower branches, and there is revealed an intricacy of branchwork and a tortuosity of limb such as is unattained when it stands alone in the field. The boldness with which the white oak will sometimes throw out its limbs abruptly, and twist and writhe to the outermost twig, I have never seen quite equaled in the other oaks. The live oak, it must be admitted, is even more abrupt where the limb divides from the trunk, but 
it does not continue its vagaries to the end.

It is to be noted that these forms are not without a purpose and a meaning. Under difficulties and obstacles the twigs and branches have groped their way; often one part has been sacrificed for the good of another, in order that all gifts of air, and moisture, and light might be received in the fullness of their worth. Thus the entire framework of the tree becomes infused with life and meaning, almost with sense, and its character is reflected in its expression.

The observer is also impressed by the character of the foliage. The leaves are usually rather blunt and ponderous, varying a little-as, indeed, do those of several other trees 
- according to the nature of their environment. They clothe the tree in profusion, but do not hide the beauty of the ramification of its branches. In truth, they are not devoid of beauty themselves. It was natural for Lowell to exclaim,-
A little of thy steadfastness,
Rounded with leafy gracefulness, old oak, give me.

While the leaves of the white oak do not deflect and curve as much in their growth as those of some of the more graceful and elegant trees, they nevertheless fall into natural and pleasing groups, unfolding a pretty variation as they work out their patient spiral ascent, leaf after leaf, round the stemlet; showing a changefulness in the sizes of 


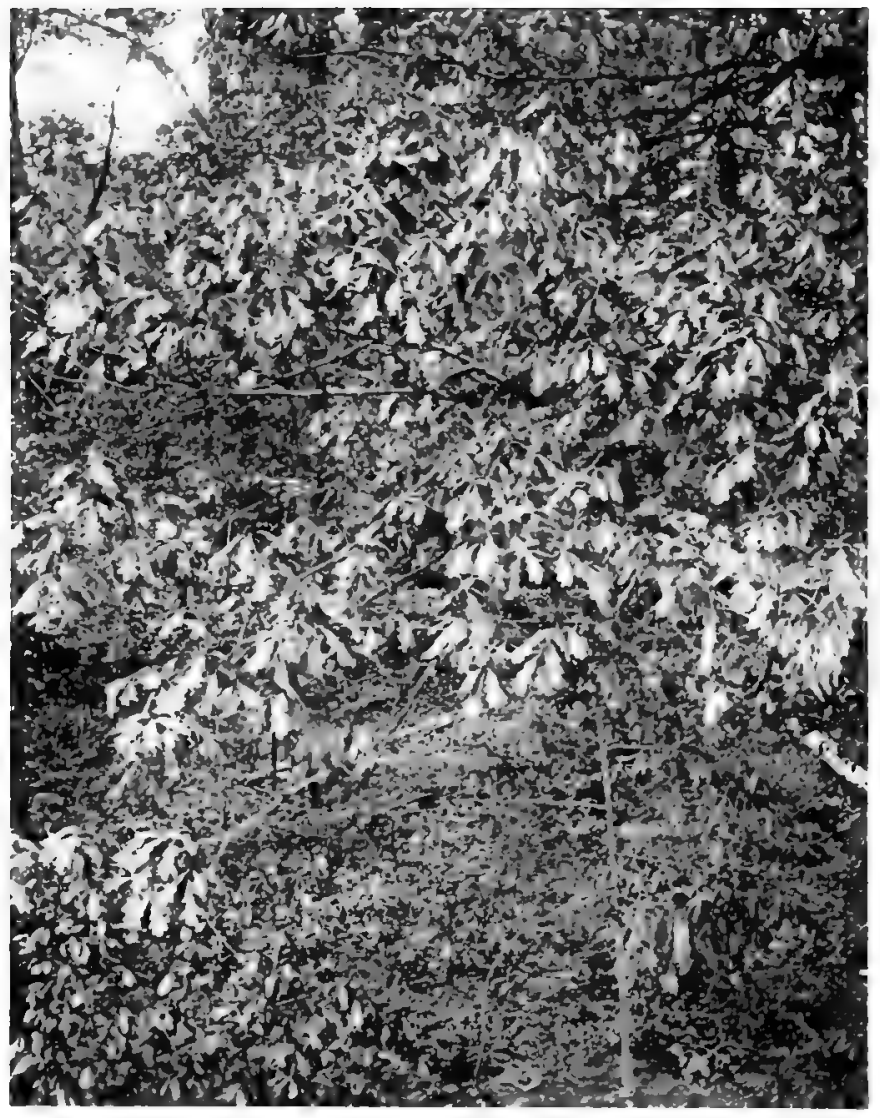

Foliage of the White Oak 



\section{FOREST TREES}

the several leaves, and a chcice in the spacing. In the first weeks of leafingtime there is to be added to these features the effects derived from transitions of color in the leaves. For the very young leaves are not green, but of a deep rose or dusky gray. They are velvety in texture, and lie nestling within the groups of the larger green leaves that have preceded them. Just as it was said a little while ago that there was expressiveness throughout the branches, it may now be said that there is a fitness of the foliage for all parts of the tree.

In winter, however, the beauty of the oak's foliage is gone. The dry leaves still hang on the boughs, sometimes even until spring, but they look disheveled and dreary. Still, they are not 
without some esthetic value, though it be through the sense of hearing instead of sight. Thoreau says, -

"The dry rustle of the withered oakleaves is the voice of the wood in winter. It sounds like the roar of the sea, and is inspirating like that, suggesting how all the land is seacoast to the aërial ocean."

Deep and glorious, too, is the light that rests in the oak woods on midsummer days. It filters, softened and subdued, through the wealth of foliage, and wraps us in a mellow radiance. Its purity and calm depth lift the senses to a higher level. Most limpid is the light in a misty shower, when the sun is low and the level rays break through the moist leaves and dampened air, while we stand within and see everything bathed in a golden luster. 
Our common chestnut is of less economic value than the oak, but one suggests the other, for the two are often found together and are similar in size and habit. The chestnut is, in truth, one of our finest deciduous trees. It has a luxuriance of healthy, darkgreen foliage, and is happy-looking in its abundance of yellow-tasseled blossoms. It is even more beautiful in August, when the young burs mingle their even tinge of brown with the fresh green of the glossy leaves. In old age it has the same firmness that is so noticeable in the oak, and seems to be just as regardless of the winds and gales.

The character of the leaf and the manner in which the branches of a tree divide and ramify have so much to do 


\section{FOREST TREES AND FOREST SCENERY}

with certain beautiful effects, that I shall make some remarks on these features in two of our maples. The sugar or hard maple is the most useful member of this genus, and may advantageously be compared with the red maple, which is perhaps more beautiful.

It is of great advantage to both of these trees that the sweep of their branches, which is carried out in ample, undulating lines, is in perfect harmony with the elegance of their foliage. In the sugar maple the latter spreads over the boughs in soft and pleasing contours. The leaves are a trifle larger than those of the red maple, and their edges are wavy or flowing, while their surfaces are slightly undulating and have less luster than those of the other tree. They are thus well fitted to receive a 


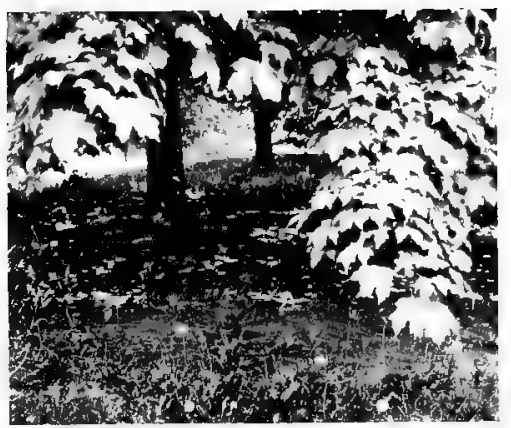

Spray of the Sugar Maple

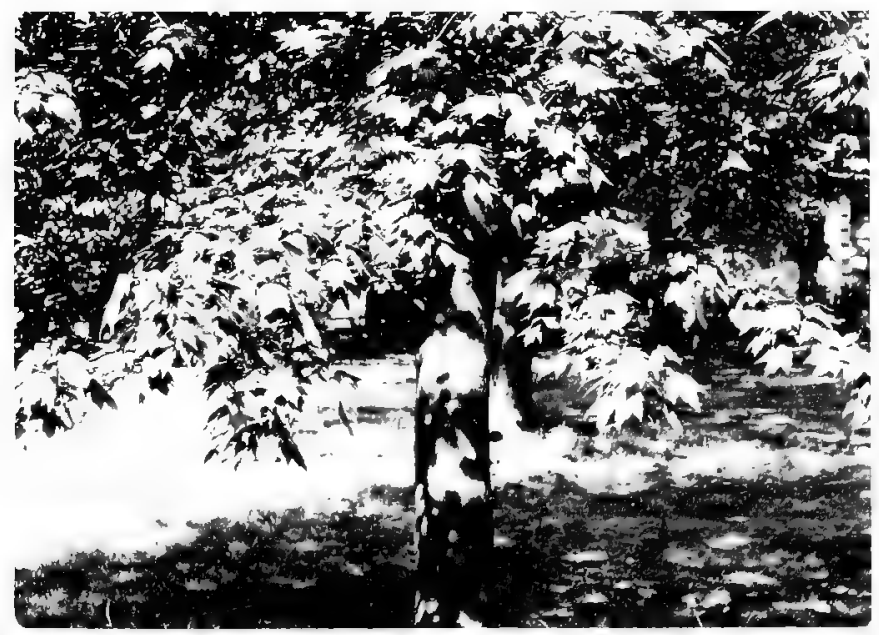

Spray of the Red Maple 



\section{FOREST TREES}

flood of light without being in danger of presenting a clotted appearance. The petioles, or little leaf-stems, assume a more horizontal position than they do in the red maple, and the twigs are usually shorter, which allows a denser richness in the foliage, which every breeze plays upon and ruffles as it passes by.

The red maple has a more airy look. This is due partly to the character of the leaf, but primarily to that of the branchwork. The main branches spread out in easy, flowing lines, much as they do in the sugar maple; but they assume an ampler range, and the last divisions, the twigs, take on decided curves, rising to right and left. On these the leaves multiply, each leaf poised lightly upon its curved petiole. 
As compared with the leaf of its congener, that of the red maple is firmer and a shade lighter, especially underneath. It is also more agile in the wind. The effect of the whole is more that of a shower of foliage than of pillowed masses. The curving lines, the elastic spring of every part, and a kind of freedom among the many leaves, make the red maple one of the cheerfullest of trees.

The sugar maple is the larger of the two, and seeks the intervales and uplands, where its size is well set off in the landscape. The red maple, which finds its natural home along riverbanks and in moist places, is interesting at all seasons. When young it is particularly attractive in summer where it fringes lakes and streams. In winter 
its bright, red twigs present a pleasing contrast to the gray bark or to the snow-covered earth. In the earliest days of spring the little scarlet blossoms break out in tufts that soon ripen into brilliant little keys, looking very pretty where they intermingle with the pale green of the opening leaves.

There is, in fact, more color in the woods in the opening days of spring than is generally admitted or noticed. Many kinds of trees unfold their leaves in some tender shade of rose or golden brown; while others lend a distinct color to a whole section of forest by the opening of their early blossoms.

The maples, however, are chiefly famous for their wonderful richness of color in the fall of the year; particularly the sugar and the red maple, whose 
brilliancy at this season it would be difficult to match. They exhibit, in truth, a gamut of beautiful tones, from pale yellow to deep orange, and from bright scarlet to vivid crimson. They are among the first to change the color of their leaves, but are quickly followed by other species of trees, whose varying hues blend together and enrich the autumn landscape. The "scarlet" and "red" oaks now justify their names; the flowering dogwood and the sweet gum show their soft depth of purple; the milder tulip tree takes on a golden tint and shimmers in the sun, mingling with ruddy hornbeams, browned beeches, variegated sassafras trees, or the fiery foliage of the tupelos. The swamps are aflame with the brilliancy of red maples, con- 
trasting with the quieter tones of alders and willows.

We may speak of brilliancy and color in our leafy woods at the ebbtide of the year; but to know their beauty well we must walk among the trees. Nor can pictures tell us all the truth about the tints of autumn. How should we receive from them the atmospheric effects that nature gives, and the indescribable blending and softening that comes from innumerable rays of diffused and reflected light? The beauty also changes from day to day and from hour to hour, for weeks.

Some of the other broadleaf trees deserve to be noticed, though in less detail, as objects of beauty in the forest. The honey locust, one of our largest trees of this class, is distinguished 
principally for the elegant forms of its branches. The smaller divisions, the twigs, follow a zigzag course which in itself is not beautiful, but the effect is so bound up with the complex spiral evolutions of the larger divisions, the boughs and branches, that the result is only to heighten the elegance of the latter. The foliage of this tree is very delicate, being composed of numerous elliptically shaped leaflets, that are gathered into sprays that hang airily among the bold and sweeping boughs.

Much might be said here in commendation of the sassafras tree, were it economically more important. Its brown, sculptured bark is very attractive, and its yellowish blossoms, that break in early spring, are fragrant. The leaves are of several shades of 
green, and vary considerably in outline. When in full leaf, the outward form of the tree is striking in appearance, its foliage being massed into rounded and hemispherical shapes that group themselves in the crown of the tree in well-proportioned and tasteful outlines.

The birches, too, are very attractive trees, especially where they have ample room to develop. The white birch appears at its best where it is sprinkled in moderation among open groves of other trees. To the forester it is of some importance, as its seedlings rapidly cover denuded or burnt areas. They also shield from excessive sunlight or from frost the seedlings of more valuable kinds that may have sprouted in their welcome shade; until, 


\section{FOREST TREES AND FOREST SCENERY}

gaining strength, the latter after a few years push up their tops between the open foliage of their protecting "nurses." The white birch may be seen performing this good office in many a fire-scarred piece of woodland throughout the Northeastern States. Often, too, we see it standing a little apart, as at the edge of a forest; its slender branches drooping around the pure white trunk and its agile leaves gleaming as they wave in the light breeze. It is like one of those single notes in music that glide into universal harmony with irresistible charm.

The yellow birch, on the contrary, is most beautiful in the depth of the forest. It is a large, useful tree. In the Adirondacks I have often admired its tall, straight trunk as it rose above 


\section{FOREST TREES}

the neighboring firs and spruces and unfolded its large, regular crown of dense dark foliage, relieved underneath by the thin, shining, silvery to goldenyellow bark, torn here and there into shreds that curled back upon themselves around the stem.

The white elm, well represented in the avenues of New England, is widely distributed. It is a tree for the meadow, although its natural grace and, one might almost say, inborn gentleness are preserved along the fringes of the forest and on the banks of streams. It needs some room to show the refinement of its closely interwoven spray. Watch its beauty as it sways in the light wind; or look at a grove of elms after a hoar-frost on some early morning in winter, when the leaves are 
gone and all its outlines are penciled in finest silver.

The flowering dogwood is one of our smaller trees, but is exceptionally favored with all manner of beauty. Although it is very common in many of the States, and is not without its special uses, it occupies a subordinate position in the eyes of the forester, being often no more than a mere shrub in form. And yet, while some of the larger trees by their majestic presence lend grandeur to the forest, the dogwood brings to it a charm not easily forgotten. In spring, when it is showered all over with interesting, large, creamy-white flowers, it is an emblem of purity. Its leaves, which appear very soon after the bloom, are elegantly curved in outline, soft of tex- 


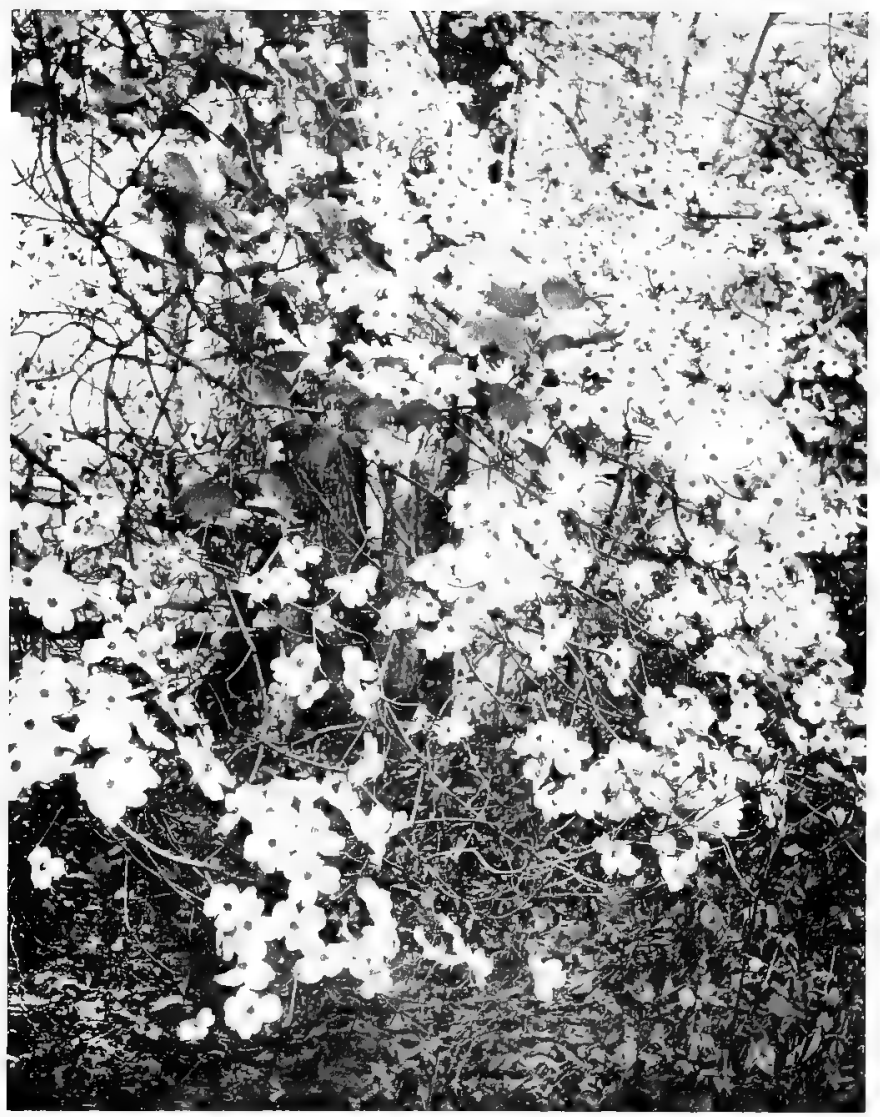

The Dogwood in Bloom 

ture, light-green in summer, and of a deep crimson or rich purple-maroon in autumn. ${ }^{2}$ In winter the flowers are replaced by bright, red berries. Its spray of twigs and branchlets, formed by a succession of exquisitely proportioned waves and upward curves, is not as conspicuous, though hardly less ornamental at this season than the fruit.

As a shrub, being among the very first to bloom, it decorates the forest borders in spring, or stands conspicuously within the forest. It is found everywhere in the Appalachian region. In the coastal plain it is associated with the longleaf pine, or may be seen among broadleaf trees, or standing among red junipers, as tall as they and quite at home in their company. 
Before turning to coniferous trees, the tulip tree deserves some attention on account of its usefulness, its extended habitat, and its beauty as a forest tree. It is closely related to the magnolias, to which belongs the big laurel of the Gulf region, an evergreen species that might be called the queen of all broadleaf trees. But the big laurel must here give place to the tulip tree, because it is not so distinctively a forest tree, and is much more restricted in its geographical distribution.

The first general impression of the tulip tree is, I venture to say, one of strangeness. There is a foreign look about the heavy, truncated leaves, and an oriental luxury in the large, greenish-yellow flowers. These appear in May or June, while the conelike fruit 
ripens in the fall. When the seeds have scattered, the open cones, upright in position, remain for a long time on the tree, where they are strikingly ornamental.

Esthetically the most important feature of the tulip tree is an expression of dignity and stateliness, which gives it a character of its own. Its extraordinary size renders it a conspicuous object in the forest, the more so because we usually find it associated with a variety of other trees of quite different aspect. Michaux, who has told us much about the forest flora of the eastern United States, could find no tree among the deciduous kinds, except the buttonwood, that would bear comparison with it in size, and he calls it "one of the most magnificent vegetables of 
the temperate zone." Its columnar trunk continues with unusual straightness and regularity nearly to the summit of the tree. Its limbs and branches divide in harmonious proportions, reaching out as if conscious of their strength, and yet with sufficient gracefulness to lend dignity to the tree. The lower boughs, especially, are inclined to assume an elegant sweep, deflecting sidewise to the earth, and ending with an upward curve and a droop at the outer extremity. Often the crowded environment of the forest does not admit of such ample development; yet even under such conditions the tulip tree preserves much of its elegance and is generally well balanced.

When young it does not appear to much advantage, being rather too sym- 


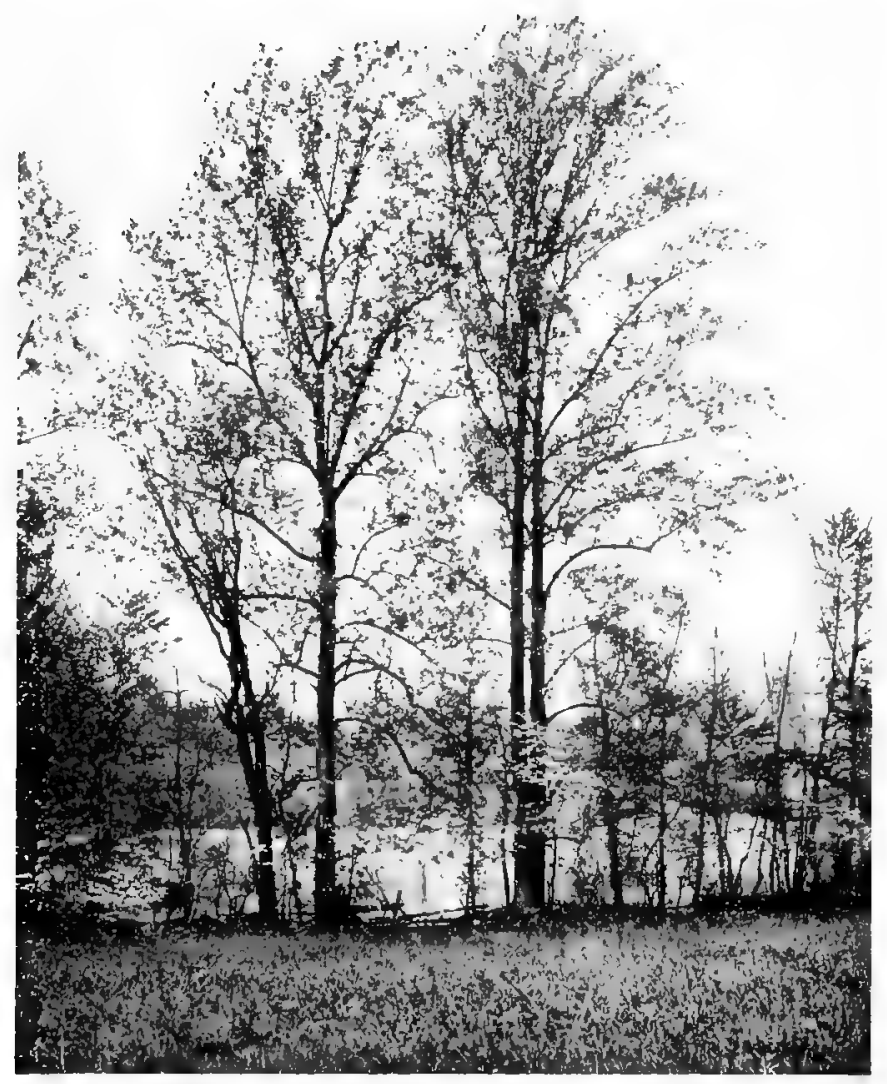

Tulip Trees 

metrical. Nevertheless I have found it described as a tree of "great refinement of expression" at that age. As soon as it begins to put on a richer crown of foliage and to develop a sturdier stem and more elegant lines in the disposition of its branches, it becomes invested with its peculiar aspect of magnificence, increasing in gracefulness and grandeur from year to year. Its bark, at first smooth and gray, gradually becomes chiseled with sharp small cuts; then takes on a corrugated appearance, becomes brown, and finally turns into deeply furrowed ridges in the old tree. Now the foliage, too, seems to clothe the massive boughs more fitly, being denser and in size of leaves more in accordance with the increased dimensions of the tree. 
The foliage of the tulip tree is, in truth, one of its principal points of beauty, and is inferior only to the stateliness of its form. The opening leafbuds are conical, exquisitely modeled, and of the tenderest green. The leaves unfold from them much as do the petals in a flower, but quickly spread apart on the stem. As they grow larger they still preserve their light-green color, but take on a mild gloss. They are ready to shift and tremble on their long leaf-stalks in every breath of wind, which gives them a decided air of cheerfulness. We may see the same thing in the aspen and in some of the poplars. Under the tulip tree, however, the light that descends and spreads out on the ground is far superior. It is softer 
and purer. We need not look ùp to appreciate it, but may watch it on the soil, over which it moves in flecks of light and dark.

"The chequer'd earth seems restless as a flood

Brushed by the winds, so sportive is the light

Shot through the boughs; it dances, as they dance,

Shadow and sunshine intermingling quick,

And dark'ning, and enlight'ning (as the leaves

Play wanton) every part."

THE CONE-BEARERS

The cone-bearing trees are usually provided with needle-shaped or awlshaped leaves, in contradistinction to the broad and flat ones that belong 
to the group described in the preceding section of this chapter. Most of them preserve their foliage through the winter, and are commonly recognized by this evergreen habit. They are much more important to the forester than the other class. The conifers grow on the true forest soils. They range along mountain crests or are scattered over dry and semi-arid regions or along the sandy seashore, while the broadleaf species usually require a better soil and a more congenial climate. This circumstance causes many deciduous forests to be cut down, in order that the better land on which they grow may be utilized for agricultural purposes. Moreover, the wood of the conifers is generally more useful, being in several of the 
species of great economic importance. Lastly, in their habit of denser growth, and from the fact that these trees are ordinarily found in the form of "pure" forests (in contradistinction to those forests in which a number of species grow intermingled), they furnish certain very important conditions for practical and successful forestry.

The common white pine well deserves to stand at the head of all the conifers or evergreens east of the Mississippi. Though it once covered vast areas in more or less "pure" forests it has been largely cut away, and recurring fires have generally prevented its return; but in certain places it could even now be restored by careful treatment. At present the last remnants of these pineries are disappearing swiftly, 
and before the methods of the forester can be applied to such extensive areas, this valuable heritage will probably have vanished. Heretofore it has been to us Americans in the supply of wood what bread and water are in daily life. It has been hardly less valued by other nations, having been planted as a forest tree in Germany a full century ago.

I cannot say what I admire most in the white pine; whether it be the luxuriance and purity of its foliage, or the very graceful spread of its boughs. There is hardly a tree that can equal it for softness and rich color. The tufts of needlelike leaves densely cover the upper surfaces of the spreading branches, and are of a mild, uniformly pure olive-green. Seen from beneath they appear tangled in the 


\section{FOREST TREES}

beautifully interwoven twigs and stems. It is here that we first begin to notice the exquisite manner of the white pine. The boughs reach out horizontally, with here and there one that ascends or turns aside to assume a position exceptionally graceful and to fill out a space that seems specially to have been vacated for it. I speak of the white pine at the age preceding maturity, when it is in its full strength, but before it has attained the picturesqueness of old age. Following an easy curve, the branch divides at right and left into dozens of finer branchlets, all extending forward and straining, as it were, to reach the light; and these in turn lift up hundreds of twigs and little stems to enrich the upper surfaces with bushy tufts of lithe green 
needles. The elegance of this habit in the white pine appears to advantage when we stand a little above it on a gentle slope and see the branches clearly defined against the surface of a lake below or some far-away gray cloud.

Both in middle age and when it is old the white pine is a distinguishedlooking tree. When young it is sometimes elegantly symmetrical; but more often, owing to a crowded position, it lacks the air of neatness that belongs to a few of the other pines and to most of the firs. At maturity it is a very impressive tree, especially in the dense forest, where it develops a tall, dark, stately stem. In its declining years the branches begin to break and fall away, no longer able to bear the weight 


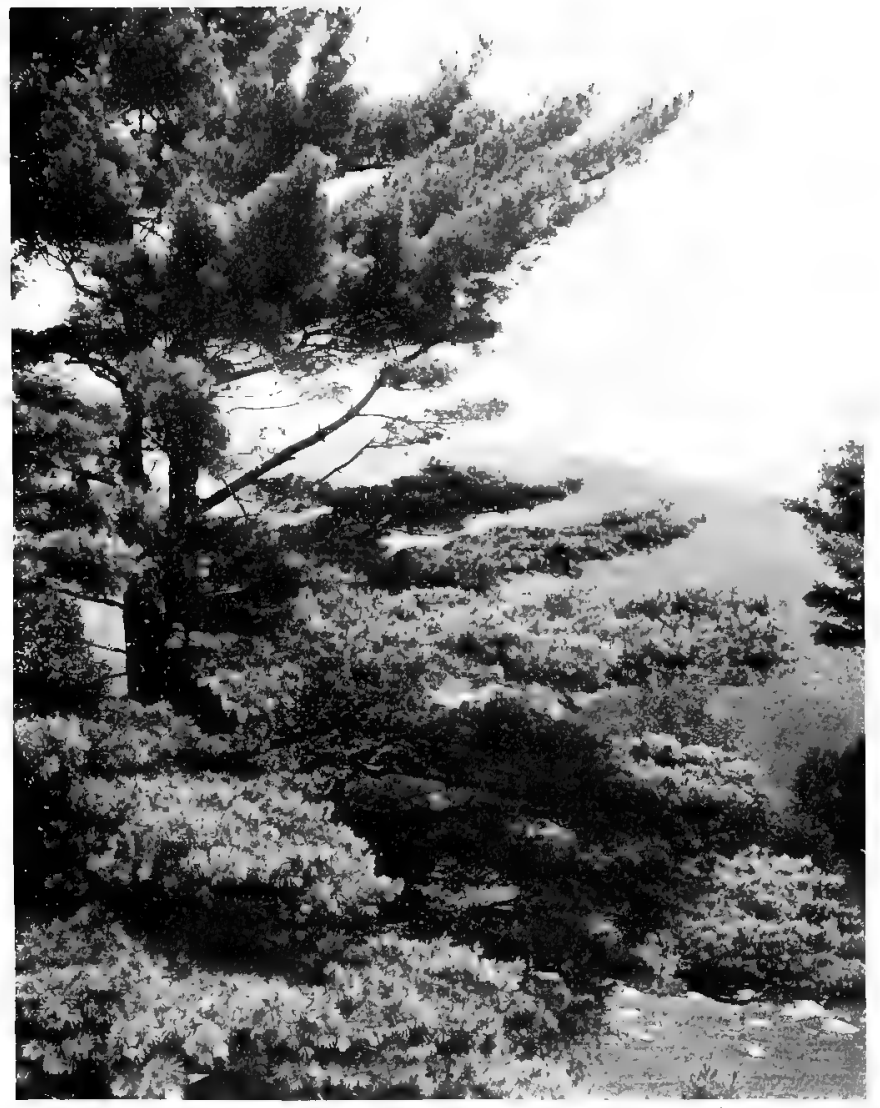

Character of the White Pine. 

of heavy snows. This is often the time when it is most picturesque.

The representatives of the white pine in the West are the silver pine and the sugar pine. Though both may be easily recognized as near relatives of the eastern species, either by the typical form of the cones or by the plan and structure of the foliage, each of the western trees possesses a majesty and beauty of its own. The silver pine is more compact in its branches than the white pine, and has somewhat denser and more rigid foliage. Its dark aspect is well suited to the mountains and ridges of the Northwest, where it commonly abounds. The sugar pine, which is the tallest of all pines, impresses us by its picturesque individuality. Its great perpendicular trunk not infrequently 
rises, clear of limbs, to the height of a hundred and fifty feet, and is surmounted by an open pyramidal crown of half that length, composed of long and slender branches that are full of motion. While the texture of the foliage is not as delicate as in the white pine, it is smooth and elastic, and has an even bluish tinge that shows to great advantage when the needles are stirred by the wind. Its cones, which are of enormous size, hang in clusters from the extremities of the distant boughs, which droop beneath the unusual weight. Two of these cones, which I have lying before me, measure each nineteen inches in length. Well might Douglas, the botanist who named this tree, call it "the most princely of the genus."

The longleaf pines of the Southern 


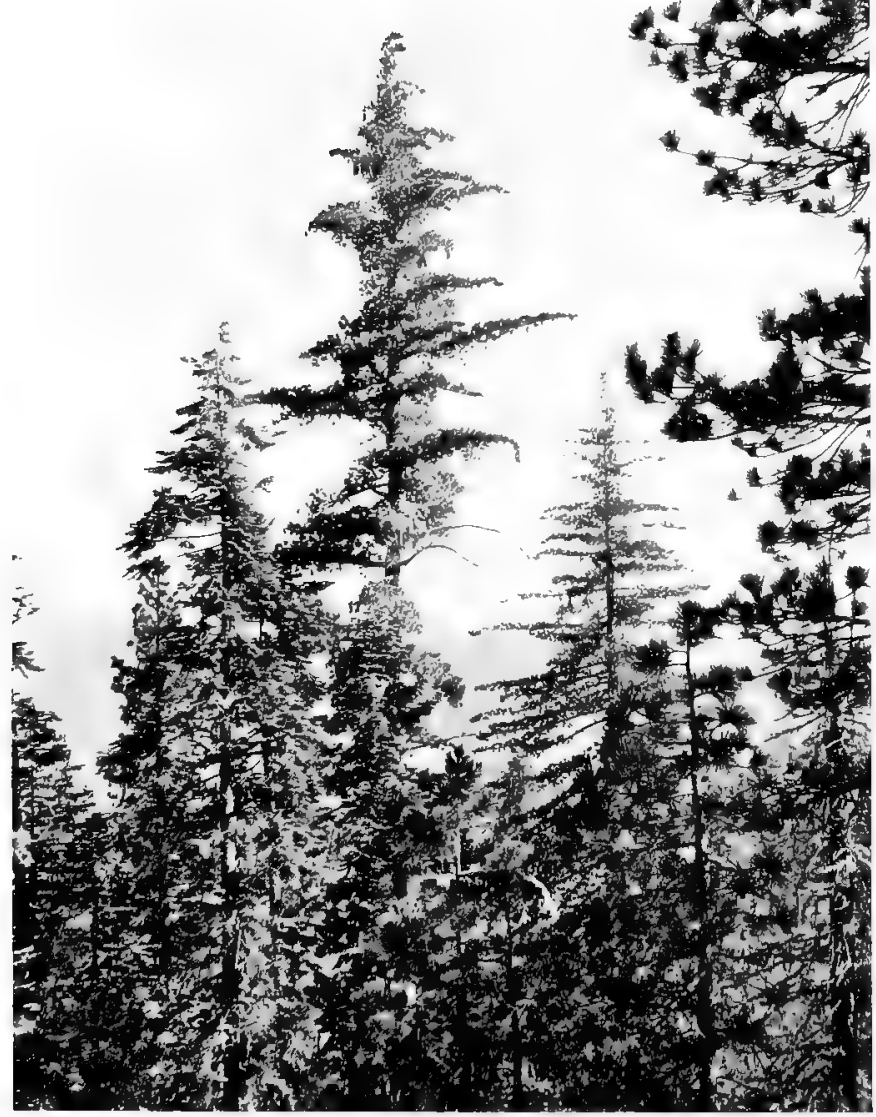

Sugar Pines

Young Bull Pines in the foregrome at the right and an Incense ('edar at the left. 

States should be noticed for their picturesqueness. The Cuban pine is restricted to isolated tracts in the region of the Gulf and eastern Georgia. The loblolly pine and the longleaf pine, near relatives of the Cuban pine, cover extensive tracts in low, level regions of the Southern States, and are most interesting in old age. Standing, it may be, on a sandy plain not far from the sea, among straggling palmettos, they lift their ample crowns well up on their tall, straight stems, and contort their branches into surprising forms; so that, looking through their crowns at a distance in the dry, hazy air of the South, with possibly a red sunset sky for a background, they are extremely fantastic and entertaining.

There are two other pines that have 37 


\section{FOREST TREES AND FOREST SCENERY}

a similar tortuous habit in the growth of their branches: the pitch pine of our eastern coast States and the lodgepole pine of the Rocky Mountains. These, however, have an esthetic value for quite a different reason. In the case of the pitch pine it is due to a natural peculiarity otherwise rare among conifers; for, this tree has the power of sprouting afresh from the stump that has been left after cutting or forest fires, thus healing in time the raggedness and devastation resulting from necessity, neglect, or indifference. The lodgepole pine of the West performs the same patient work over burned areas through the remarkable power of germination belonging to its seeds, even after being scorched by fire. Thus both of these trees not only fur- 


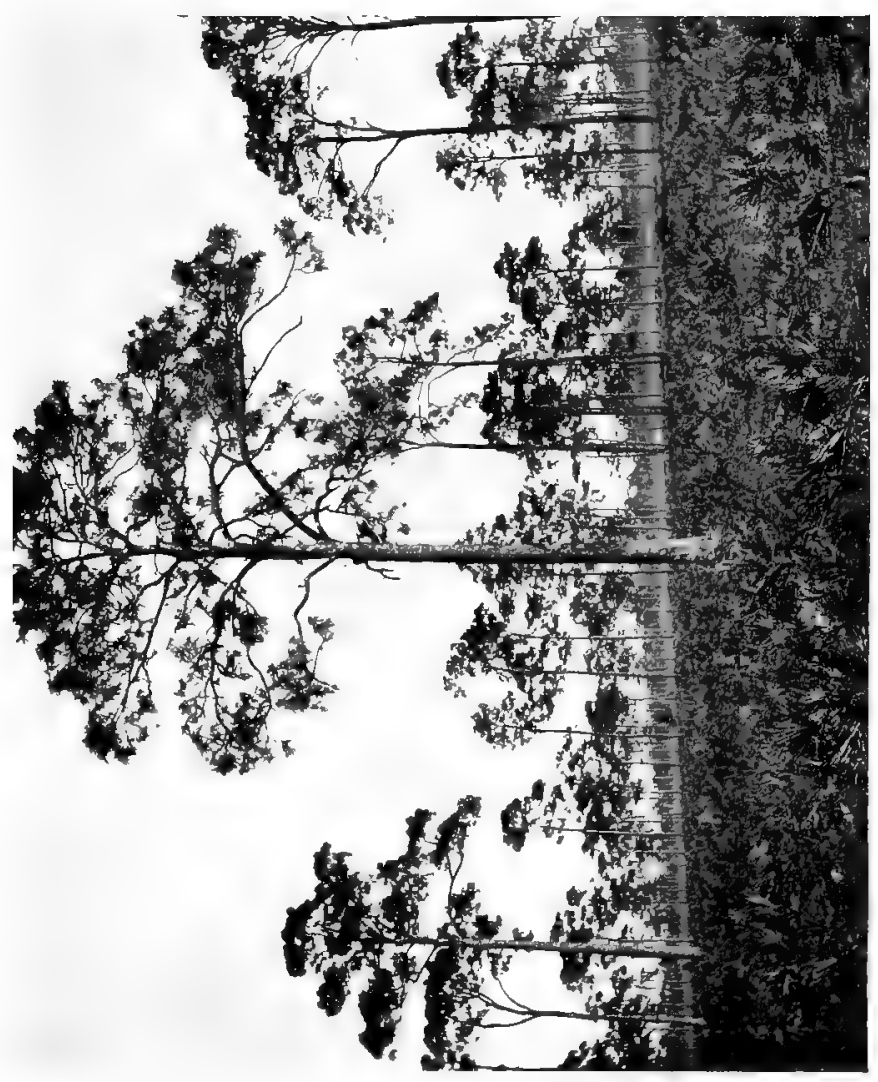

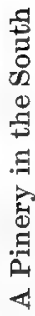

है 

nish useful material, but restore health and calmness to the forest.

In connection with the longleaf pines of the Southern States, the bull pine of the West deserves to be noticed on account of its rear botanical relationship and the somewhat similar economic position which it occupies. It is the most widely distributed of western trees, being found in almost every kind of soil and climate along the Pacific coast and throughout the Rockies. Over so wide a range, growing under very different conditions of soil, temperature, light, and moisture, it varies greatly in form and appearance. We encounter it on dry, sterile slopes or elevated plateaux in the interior, and walk for miles through the monotony of these dark bull pine forests, in which 
the trees are of small stature and seem to be struggling for their life. Again we meet it on the humid western slopes of the Sierra Nevada, associated with the sugar pine and other lofty trees. Here we scarcely recognize it. It holds its own among the company of giants, and is full of vitality, freedom, and strength; with brighter, redder bark and stout, sinuous branches; with longer needles and larger cones. The sunlight fills its ample crown spaces, and the wind murmurs in the foliage overhead; for the pines are the master musicians of the woods.

The Southern States and the Gulf region furnish us with a conifer of striking originality and great usefulness. This is the bald cypress, which may have caught the reader's eye in 


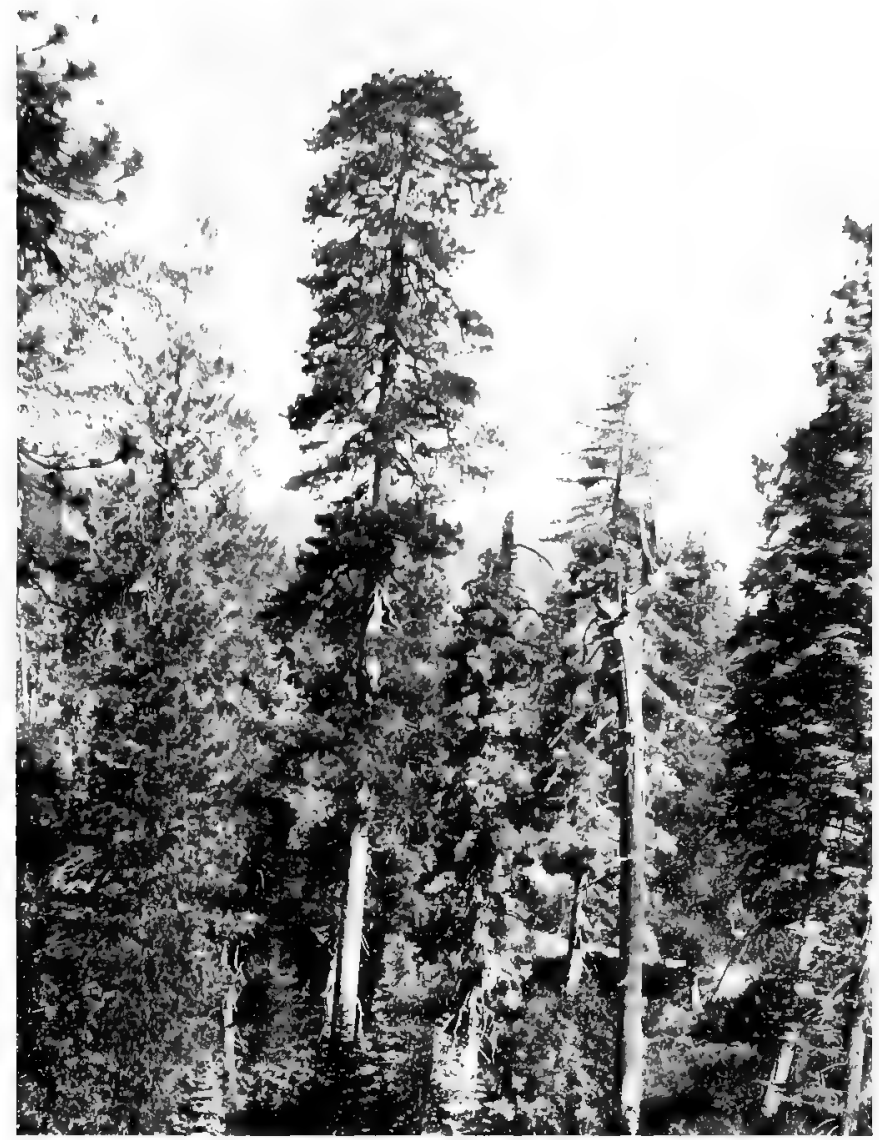

The Bull Pine in its California Home 

some northern park by the elegant forms of its spirelike growth. It rises high and erect, a narrow pyramid clothed in the lightest green foliage. The latter is composed of delicate feathers of little elliptical leaves that hang drooping among the finely interwoven short branches. This is in its cultivated northern home, where it seems to thrive well on the carefully kept greensward. But in reality it is a tree of deep swamps, seeking the dank, flooded shores of southern rivers, or impenetrable morasses, where few other trees can live. Here we may paddle our boat through the strange-looking cypress knees that it sends up above the water from the roots in the muddy soil beneath, and may admire the straight, firm trunks that are ridged and but- 


\section{FOREST TREES AND FOREST SCENERY}

tressed below to form wide, spreading bases. In this, its native home, when it has grown to maturity, it looks far different from the trim, tall pyramid that we see in the park. In place of the lofty spire it bears a broad, flat crown, that is poised upon the tall, fibrous, reddish-gray trunk. Such crowns, if the tree has had room to spread, may measure as much as a hundred feet across; but where closely pressed at the sides by other trees, they are contracted to much narrower dimensions. The foliage is soft in texture as ever, and interspersed with little globular cones. With the coming of winter, however, the sprays of foliage turn brown and fall from the tree, the bald cypress being one of the very few cone-bearers that shed their leaves. 
In the South, especially in Florida and along the Gulf, the cypress trees are likely to be overloaded with streamers of gray, mosslike tillandsia. This epiphytic plant, commonly known as "Florida moss" or "hanging moss," sometimes hides the entire mass of foliage, and lends a funereal aspect to whole groves and forests of these trees, detracting much from their beauty.

One of the prettiest coniferous trees in the Elast is the hemlock. Whatever may be the prejudice against the commercial qualities of this tree,-for the value of its wood is not now appreciated as it should be,-its appearance is admired by all who know it. I call it "pretty" because it is fine and neat when young and grows to be 
comely and graceful in middle age, rather than beautiful in the ordinary meaning of that word. It is an easy, airy tree. And yet the time comes when it loses its ease and grace, when its trunk grows darker and its boughs become straggly and rough, when it puts on the strength of age without its decrepitude and bears unflinchingly the weight of winter snows. Is it now less interesting than in its youth? I think not. It makes the woods rough and natural, and we admire its simplicity, self-sufficiency, and endurance.

When young there is no tree with such elegant and yet loose and pretty effects in the foliage, unless it should be one of its western cousins. The spray hangs delicately from the sides of the tree and the top is gracefully 
pendent. The little shoots, as they peep out from hundreds of recesses, buoyant and lifelike, and the pendent top, are in some way suggestive of a playing fountain, especially in quite young trees. In the forest the symmetry of the hemlock is not always preserved; yet it fits into the scene gracefully, whether fringing the mountain stream or grouping itself among the other trees of the forest.

The two western hemlocks also have exceedingly graceful sprays and majestic forms, but they are less familiar to most of us and are not as widely distributed as the smaller eastern species.

One of the trees of widest geographical range in America is the red cedar, or red juniper, as it should more prop- 


\section{FOREST TREES AND FOREST SCENERY}

erly be called. This statement remains true notwithstanding the recent discovery that the form of red juniper common to certain parts of the Rockies is distinct from the eastern tree. Though of small size, except in the bottom lands of Arkansas and Texas, it possesses some excellent qualities and is useful in many ways. It is sometimes used in cabinet work, and is one of the best materials for fence posts. The variety that grows along the Florida coast furnishes the wood for the indispensable lead pencil.

The red juniper is at its best along the border of the forest or where it strays a short distance away. Its foliage is dark and bushy, and infinitely tender and soft in appearance. In the lower Appalachian region it forms a 
fine setting for the gorgeous drifts of dogwood and redbud that skirt the forest edges. It forms changeful and interesting groups on the rocky knolls and ledges. On our Jersey shores it has a tasteful way of gathering into little companies, just near enough to the forest to belong to it, composing scenes that are pleasant to remember. Singly, on the yellow sands, the young conical red juniper edges off well against the sky. In its old age the same tree looks gnarled and picturesque, but still beautiful, with its masses of small blue-gray berries. ${ }^{3}$ Many of us remember it so by the edge of the ocean, and perhaps others, like myself, have allowed their imagination to drift and have fancied that it looked solemn and thoughtful, outlined against 
the pale-blue sky, listening to the swish and whisper of the sea.

Several cone-bearing trees of the Western States remain to be considered. These are the firs and spruces, which belong to the same class as the pines; and the big tree and redwood, relatives of the bald cypress.

The Douglas spruce, or red fir, is in reality neither a true spruce nor a fir, though it has some of the characteristics of each. It was discovered as long ago as 1795 by the famous explorer, Archibald Menzies. This species and a smaller one that grows on the arid mountains of southern California, with possibly a third that is found in Japan, constitute together the whole genus Pseudotsuga. But whatever its botanical peculiarities, the 
red fir is an important and exceedingly useful tree, especially for the purposes of practical and scientific forestry. Like the white pine it was planted long ago by those pioneers in forestry, the Germans, and has proved itself among them to be one of the few trees of foreign extraction that can be called successful.

When young, the red fir grows rapidly and symmetrically, and has a fresh, vigorous, healthy look. It then already possesses the bluish depth to its foliage that it preserves throughout life, a color that is comparable in its purity only to that of the white pine. In several of its other features, however, it changes with the lapse of years. It gradually loses the graceful lower boughs that feather to the ground in the young tree; its bark 
becomes rough and very thick; and its trunk develops into a tall, straight shaft that bears a long, spiry crown of striking symmetry, in which tier after tier of branches rises to the narrowing summit, ending some two or three hundred feet in air. This is its aspect in the favored regions of its growth, near the shores of Puget Sound and in the moist mountains of Washington and Oregon, where it once formed forests of extraordinary density and dark grandeur, portions of which are still preserved over this extensive territory.

Another important conifer is the lowland fir of the Pacific coast. All the silver firs, to which class this tree belongs, have distinct features in their foliage and a characteristic habit of growth, a description of which may 


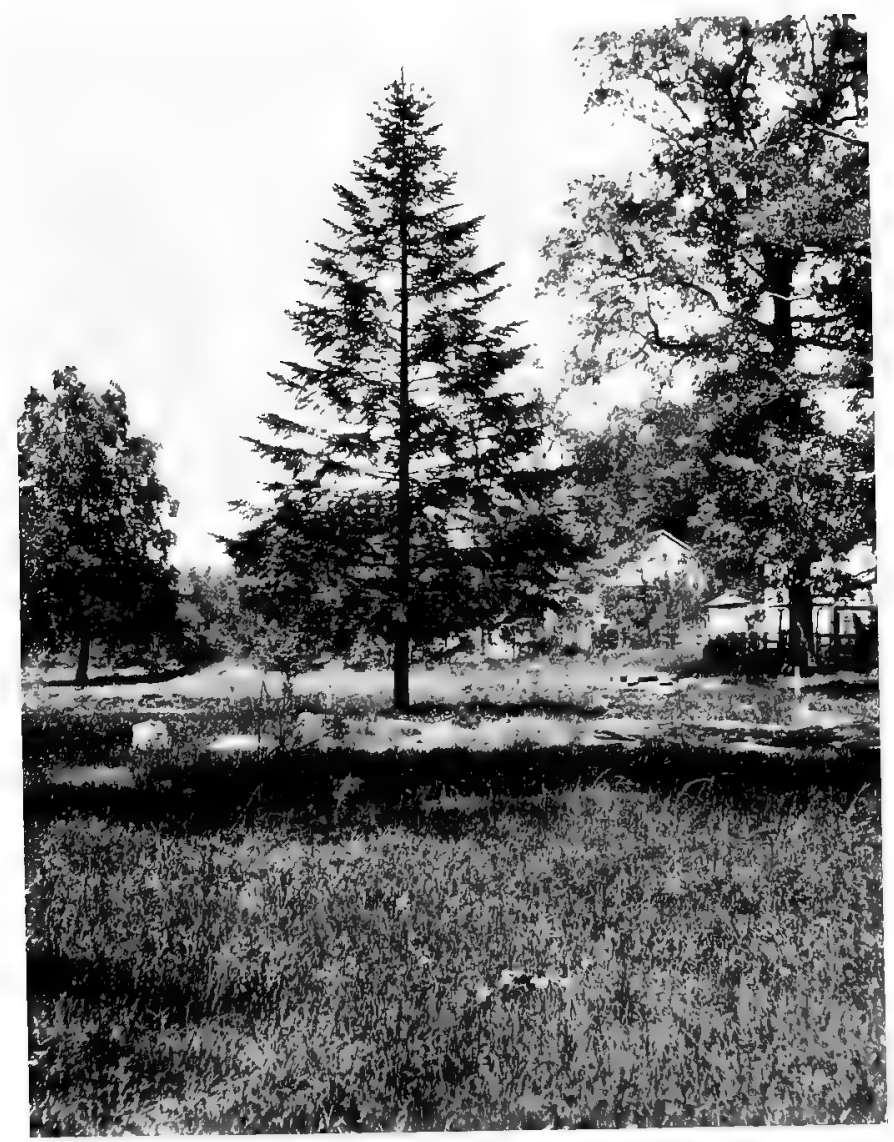

A Silver Fir at Middle Age 

enable the reader to picture to himself not only the lowland fir itself, but to form some conception of the esthetic value of the entire genus.

The leaves are narrow, flat, and linear, usually about as long as a pin or a needle, glossy green on the upper side, and streaked with a longitudinal whitish line underneath. They are crowded horizontally at the right and left sides of the shoot or twig, like the hairs on the quill of a feather. The twigs themselves, and, in turn, the boughs and branches, have a similar tendency to assume a horizontal position; and thus the tree is built up in neat symmetrical stages, dwindling in size to the summit, and presenting the typical conical form of the cone-bearers.

Let it not be presumed, however, 
that there is anything awkward or stiff in the appearance of the firs. Young firs are among the neatest and most elegant objects in a park. The smooth gray bark, the lifelike air in the distribution of the boughs and smaller branches, the glossy green as seen from the side or above, varied to a blue or gray when we stand beneath, redeem them from every charge of conventionality.

The lowland fir as a young tree, and where it is afforded sufficient room, has more of the drooping, plumelike, graceful air than is usual with the members of this genus. The leaves are somewhat curled and scattered about the stem. Like most trees it becomes more expressive as it grows older and little by little rejects the 


\section{FOREST TREES}

features and traces of its earlier years. Its arms gradually bend inward, and the whole tree becomes more cylindrical, till in its maturity it speaks freely through its broken and twisted boughs of storms and battles and insect ravages of long ago; yet it strives to cover its scars with luxuriant masses of verdure and numberless purplish cones - a truly magnificent spectacle of a hoary veteran of crisp and sturdy aspect.

The Engelmann spruce, though a smaller tree than either the red fir or the lowland fir, is one of the most important of the spruces. Its home is in the elevated regions of Colorado, whence it spreads westward and northward throughout the Rocky Mountains. Its well rounded bole is scaly with small 
cinnamon-red plates, and its foliage is composed of sharp, short, needlelike leaves, that bristle around the stem and are bluish-green in color. Its small brown cones droop from the extremities of the boughs and mass themselves in the top of the tree. Like most of the spruces, this one climbs to high elevations. Many a wild mountain slope in the West is covered by the dense ranks of these straight, slender trees, with tapering spires that are green in summer and frosted with snow and rime in winter.

The glory of our western forests, however, are the sequoias, those gigantic trees of California that have become widely famous. The two sequoias, the big tree of the Sierra Nevada and the redwood of the Pacific coast, con54 


\section{FOREST TREES}

stitute the last remnants of a mighty race that covered vast areas in North America and Europe in past geological ages. It is believed that their days are almost over, for the big tree groves are few in number and small in extent, and even these are falling rapidly under the ax and saw. Nor does this species appear to reproduce itself easily; for, although numberless seeds fall from the old trees, they rarely sprout, and therefore are slow to replace what has been taken away. The redwoods, too, are threatened with extinction, though they still cover considerable tracts along the northern half of the California coast. They are coveted even more than the big trees and are disappearing with a rapidity that only modern industry has made possible. 
Fortunately the redwood possesses two gifts of inestimable value that will prolong, but cannot perpetuate, its existence. The unusual amount of moisture in its wood and the absence of pitch in the sap lessen the danger from fire; while the same remarkable trait that we noticed in the pitch pine, otherwise very rare in coniferous trees, of sprouting from dormant buds at the edge of the stump will replace, for a time at least, many of the giants that are taken away.

The general appearance or type of the sequoias resembles that of the cypresses and cedars. The bald cypress is their nearest relative. The big tree often has the same spreading base, and both have the fluted, shreddy bark, traits that may also be noticed in 
the common white cedar and in arborvitæ. The diameter of the trunk of the big tree is strikingly large even for its wonderful height. Both trees lift their crowns rather high, and have comparatively short boughs, with dense, bushy, somewhat straggly-looking foliage. In its youthful stage the foliage of the redwood, like its congener's, has a bluish tinge, which with advancing years turns to a dark and somber green that contrasts strangely with the red color of the thick, spongy bark. But the individuality of both trees, especially that of the big tree, is so impressive and magnificent that all these minor essences become involved in the majesty of the whole. The mighty bole rises in splendid proportions to where the distant fronds hang loosely down, 
disappearing within their somber shadows, but still carrying upward the masses of foliage, as if striving to reach the very clouds. As we view their stately and incomparable forms, so masterly wrought, so unapproachable in their magnificence, we need hardly be told that these trees are strangers from a distant and forgotten age.

Much has been said and written concerning the sizes and ages of these two largest trees of America-indeed, with the exception of the Australian eucalipti, we might say of the world. It is said that some of the latter surpass the redwood in height, though a redwood tree was discovered within recent years on the Eel River, California, whose stupendous height reached nearly three hundred and fifty feet, 


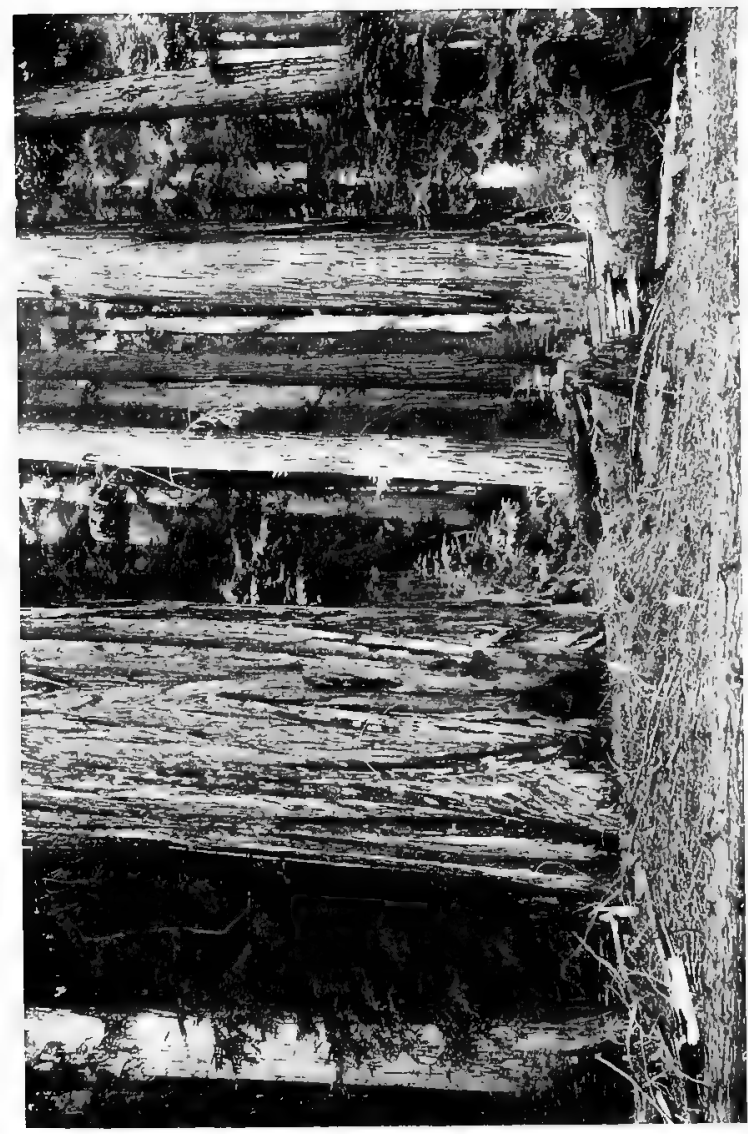



thus surpassing in that dimension, at least, any previously recorded measurements of the big tree. The ages of the sequoias have been more difficult to determine, but it appears that in the beginning they were exaggerated. The mature redwood, doubtless, is apt to be several centuries younger than the big tree; but so excellent an authority as Mr. John Muir has said of the latter that "these giants under the most favorable conditions probably live five thousand years or more, though few of even the larger trees are more than half as old."

The redwoods are great lovers of moisture. In the valleys and canyons near the ocean they bathe in the ascending fog and stand dripping with condensed vapor. We shall come upon 
them in dense groves, where the day is a continuous twilight and the trees surpass in their combined massiveness even the red firs of Oregon. At other times we shall find them mingling in more open forest with lowland firs and hemlocks, or, in their northern range, with the splendid Port Orford cedar. The light enters these more open forests and calls forth much beautiful young growth and shrubbery: the rhododendrons of California, with large and showy purplish blossoms and evergreen leaves; western dogwoods, that might at first glance be mistaken for the eastern species; barberries and familiar hazels; and ferns and violets.

The reader must not infer, of course, that such scenes are necessarily of common occurrence in the forest; but 


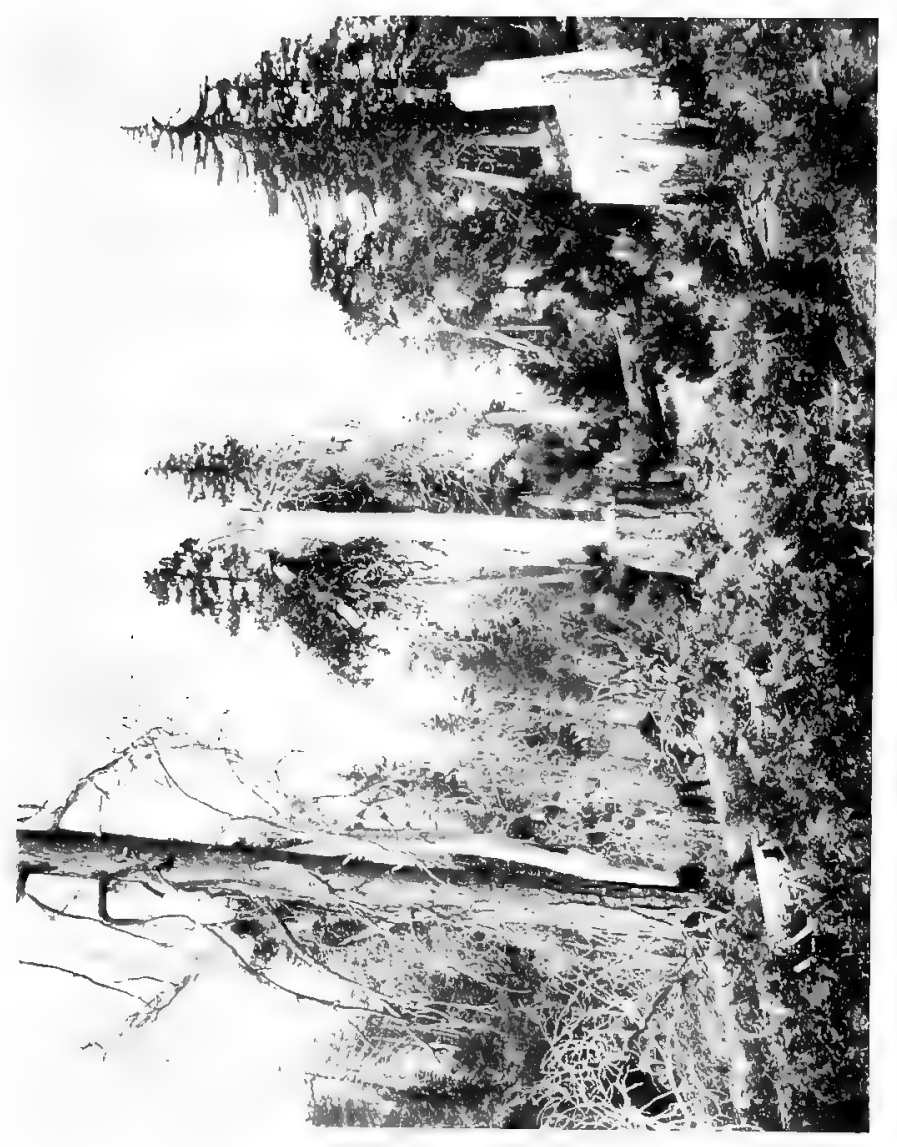

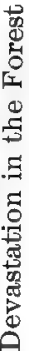




FOREST TREES AND FOREST SCENERY

the excessive or ill-timed grazing of sheep, which trample to death the young tree seedlings as they pass over the ground in great herds and devour the last vestiges of vegetation, thus leaving a bare and dry forest floor, upon which the old trees subsist with difficulty through the prolonged droughts of summer. 


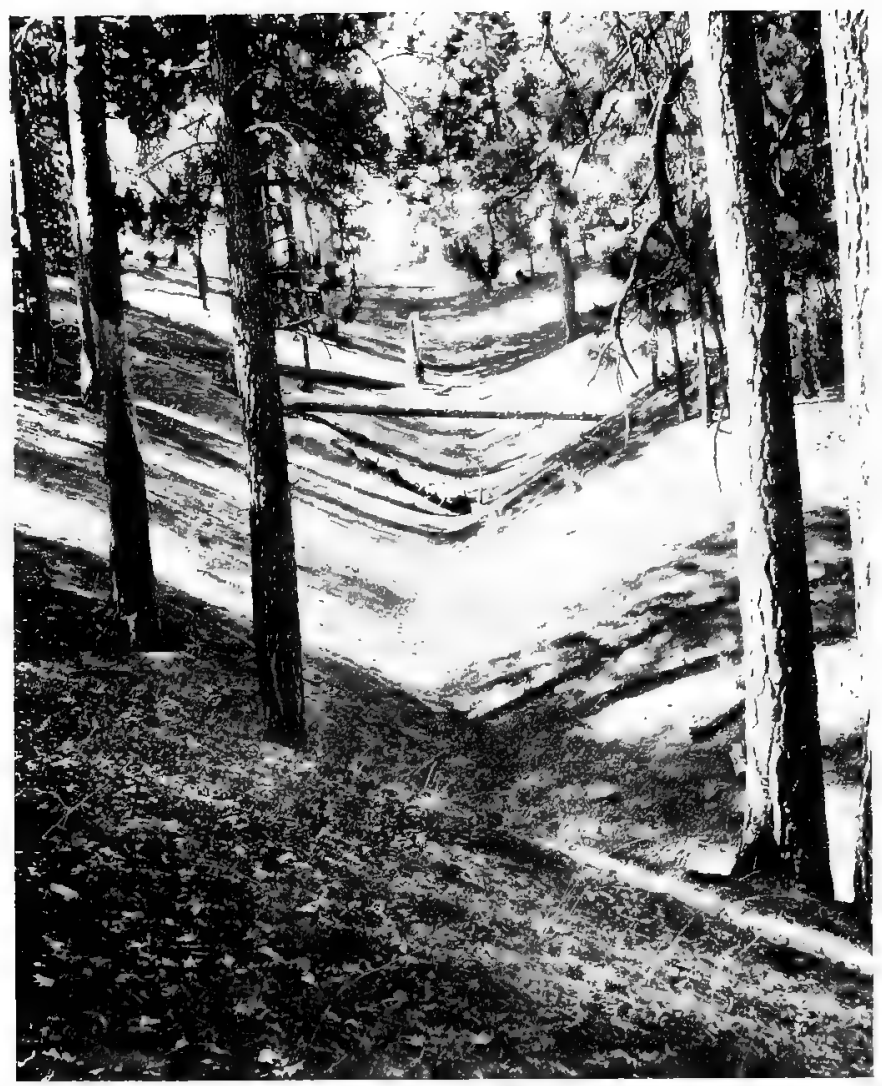

Contesy of lite Butrenut of Forpatry

Where the Sheep Have Been 



\section{II}

\section{FOREST ADORNMENT}

THOUGH there can be no forest

1 without trees, it may be asserted with equal truth that trees alone would make but an incomplete forest. ${ }^{5}$ Under the old trees we find the young saplings that are in future years to replace them and in their turn are to form a new canopy of shade. In their company is a vast variety of shrubs, ferns, and delicate grasses and flowers that decorate the forest floor. Vines and creepers gather about the old trees and clamber up their furrowed trunks. In autumn the ground is strewed with 


\section{FOREST TREES AND FOREST SCENERY}

fallen leaves, motionless or hurrying along before the wind. These gather into deep beds, soft to the tread, and at last molder away in the moist, rich earth. In the needle-bearing forests. of the mountains brilliant green mosses replace the shrubs and flowers and deck the bare brown earth.

There are lifeless sources of beauty in the woods, too, that are not easy to pass by unnoticed: rocks with interesting forms and surfaces; forms that are lifeless, yet take on distinct expression by their different modes of cleavage, and surfaces that drape themselves in the choicest paraphernalia of drooping moss and rare lichen; prattling mountain streams; cascades; and glassy pools. These are "inanimate" things with a kind of life in them, after all. 


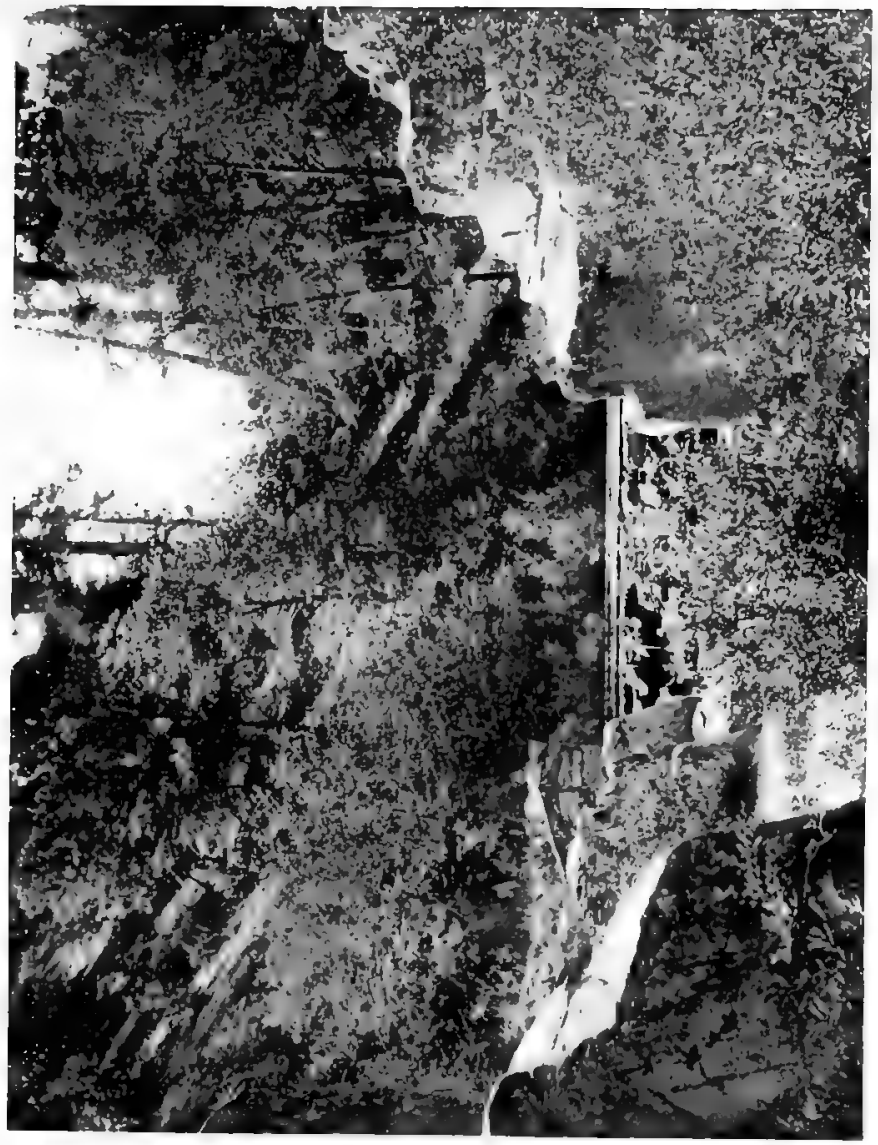

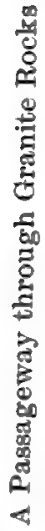

है 
Lastly, there are the true owners of the forest: the bird that hovers round its borders; the free, chattering squirrel; the casual butterfly that leads us to the flowers; and the large game that inhabits the hidden recesses and adds an element of wildness and strange attraction to these quiet haunts.

All this wealth of detail gives life to the forest. The shrubs, above the rest, should here interest us somewhat more minutely. They are often the most conspicuous objects in the embellishment of the forest; and since our investigation was to be guided to some extent by considerations of usefulness, it ought to be added that shrubs not infrequently exercise a beneficial influence on the vigor and well-being of the trees themselves. Trees, shrubs, and certain of the 
smaller plants - so long as their root systems are not too dense and intricate - are of value on account of their ameliorative effects on temperature and moisture. This is more important in this country, so extreme in its climatic variations, than in northern Europe. In the dry and parching days of summer the shrubbery of the woods, by its shade, helps to keep the earth cool and moist. This mantle of the earth, moreover, conducts the rain more gradually to the soil, exercising an efficient economy. In the fall and winter the shrubs, which are densest near the forest border, help to break the force of the sweeping winds which might otherwise carry away the fallen leaves, so useful in their turn because they are conservators and regulators of mois- 




Costrteny of the burem of Furcstry

Shrubbery and River Birches. New Jersey 

ture and contain valuable chemical constituents which they return to the soil.

The pine barrens of New Jersey illustrate these principles. In close proximity to the sea a welcome moisture enters the forest with the ocean breezes. Penetrating farther inland, it is not so entirely dissipated as to preclude a varied undergrowth of shrubbery, which in turn renders a welcome aid to the forest by the protection it affords to the porous, sandy soil, which would soon dry out under the scant shelter of the pervious pines. Under, neath these the kalmia or calico bush, with its large and showy bunches of flowers, is abundant. In late summer the sweet pepperbush is there, laden with its fragrant racemes; in winter, the cheerful evergreen holly of glossy green 
leaf and bright berry. In the dry and sunny places we find the wild rose, the trailing blackberry, with its rich color traceries on the autumn leaves, and the no less brilliant leaves of the wild strawberries underfoot. We come upon the creeping wintergreen and the local "flowering moss." The fragrant "trailing arbutus," here as elsewhere, is an earnest of the generous returning spring. Along the creeks and brooks are masses of honeysuckles, alder bushes, and sweet magnolias.

The coniferous forests of the Rocky Mountain region are either too dry or too elevated to promote a luxuriant undergrowth; but we find it in the humid coast region of Oregon and Washington, within the forests of fir, pine, and spruce. In the deciduous 



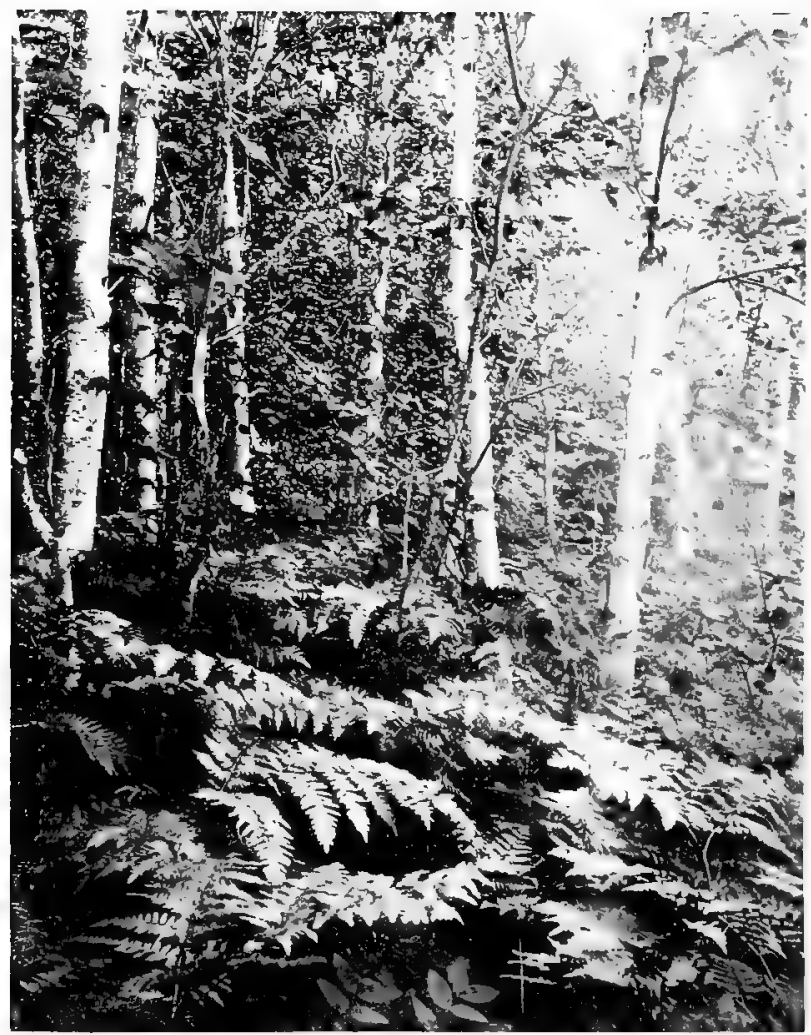

Fern Patch in a Grove of White Birch 
forests, however, the shrubbery attains its best development, for its presence depends largely upon moisture, climate, and soil, and these conditions are usually most favorable in our broadleaf districts. In the latter, moreover, the shrubbery exercises its influence most efficiently, for many of the pines will bear a considerable amount of heat and drought, and several other conifers show their independence and a different kind of hardihood at high and humid elevations. The varied and beautiful forms of undergrowth in our broadleaf forests - the shrubs, the vines and graceful large ferns, and the smaller plants that live along the forest borders and penetrate within - may be regarded as one of the distinctive features of American forest scenery. 
In such forests, and along their borders, the birds like to make their home. Among the bushy thickets they find a secure shelter, and some of them seek their food among the fruits and berries that grow there. They all possess their individual charms, and infuse such varied elements of life and cheer into the woods that even the most commonplace scenes are transmuted by their presence, while those that were already beautiful receive an added attraction. In winter there is nothing more harmonious than a flock of snowbirds flying over frosted evergreens toward some soft gray mist or cloud. For grace and ease of movement $I$ have never seen anything more airy than the Canada jay alighting on some near bough, softly as a snowflake, to watch 
and wait for the scraps of the forester's meal. Another interesting bird to watch in his movements is the redwinged blackbird. Out along the edges of the forest and in the swamps and marshes lying between bits of woodland, he may be seen from earliest spring to the last days of fall. ${ }^{\circ} \mathrm{We}$ cannot help watching him passing restlessly to and fro by himself, or circling happily about in the flock, returning at last to his clumps of alders and willows, or disappearing among the hazy reeds and grasses. But if, instead of grace and movement, we are more interested in sound, we shall find no songbird with sweeter notes than the thrush. Whatever added name he may bear, we are sure of a fine quality of music; music with modulating notes, 


\section{FOREST TREES AND FOREST SCENERY}

plaintive and clear, that drive away all harshness of thought.

Let us again consider the undergrowth in the forest. Where shrubs and tender growths abound the wintry season cannot be desolate or dreary. When the display of summer is over they attract the eye by their bright fruits and their habits of growth. Their branchlets are often strikingly pretty in color and well set off against the snow. Their intricate traceries of twig and stem are an interesting study. The copses of brown hazels that spread along the mountain side and the dusky alders or yellow-tinted willows are in perfect harmony with this season of the year.

It is by crowding into masses that our shrubs of brighter blossom produce 


\section{FOREST ADORNMENT}

some of the most superb effects of spring. A multitude of rhododendrons or great laurels covers some mountain side, carrying its drifts of pale rose far back into the woods. A mass of redbuds and flowering dogwoods, the former again rose-colored, the latter a creamy white, pours out from the forest's edge among ledges of rock and low hills. The wild plums and thorns, with their delicate flowers, are beautiful in the same manner, and in addition have a pretty habit of straying out and away from the woods, much like the red juniper.

Our shrubs are no less beautiful in their separate parts than they are magnificent in their united profusion. The common sweet magnolia is especially well favored. Its elegantly elliptical 
leaf, with smooth surfaces, glossy and dark green above, silken and silvery below, is one of the most attractive to be found. Its flower cannot help being beautiful, for beauty is the heritage of all the magnolias. Often, however, half the pure ivory cups lie hidden in the leaves, to surprise us on a closer approach with their beauty and sweet fragrance. Altogether this favored shrub is one of the most exquisite objects of decoration, whether in the swamp, along brooksides, or through the damp places of the forest.

The hawthorns, which, like the sweet magnolia, occur both as trees and as shrubs, combine varied forms of attractiveness, such as compound flowers of white or pinkish hue; sharply edged, elegantly pointed leaves; bright 


\section{FOREST ADORNMENT}

berries; and closely interwoven branchlets stuck about with thorns. The redbud, which I have already mentioned, holds its little bunches of flowers so lightly that they look as if they had been carried there by the wind and had caught along the twigs and branches. Very different from these, yet no less interesting in its way, is the staghorn sumach, which is of erratic growth and bears stately pyramids of velvety flowers of a dark crimson-maroon. There is a fine contrast, too, where the serviceberry, with early delicate white blossoms, blooms among the evergreens and the opening leaves of spring.

Another word about the West. The undergrowth of the northerly portion of the Pacific coast region has already been referred to; but there ex- 
tends throughout the Southwest, penetrating also northward and eastward, another kind of forest growth that is so distinct in character from all others that it should be specially described. It is, in fact, quite opposite in its nature to the shrubbery of the more humid forest regions in that it shows a tendency to seek the arid, open, sunny slopes, where it forms a scrubby, though interesting, and varied cover to the rough granite boulders and loose, gravelly soils. This growth is everywhere conveniently known as "chaparral," whether it be the low, evencolored brush on the higher mountains or the dense, scraggy, promiscuous, and impenetrable thicket of the foothills and lower and gentler slopes. The impression which the chaparral 
makes depends largely upon the distance at which it is viewed. If we stand in the midst of a dense patch of it we see of how many elements it is composed; how the shrubs of different size, shape, and character crowd each other into a tangle of branches, some not reaching above the waist, others closing in overhead. The ceanothus, with its dull, dark-green foliage and bunches of small white flowers, which appear in June, stands beside the stout-stemmed, knotty, twisted manzanita, with its strikingly reddishbrown bark and sticky, orbicular, olivecolored leaves. Among smaller shrubs we find the aromatic sage brush, of a light-gray, soft appearance, and the richer, darker, small-leaved greasewood, or chemisal, as it is more com- 


\section{FOREST TREES AND FOREST SCENERY}

monly called farther north, with its small, white-petaled flowers enclosing a greenish-yellow center. Very plentifully scattered among all these we usually find the scrubby forms of the canyon live oak and the California black oak. Here and there we may see a large golden-flowered mallow, or the queenly yucca raising its fine pyramid of cream-colored flowers out of the dense mass.

The far view is quite different. Distance smoothes the surface and somewhat obliterates the colors, though we may still distinguish a variegated appearance. The eye takes in the larger outlines and the scattered pines that sometimes occur within the chaparral. Nor is the latter, as we now perceive, always a dense growth, but may 


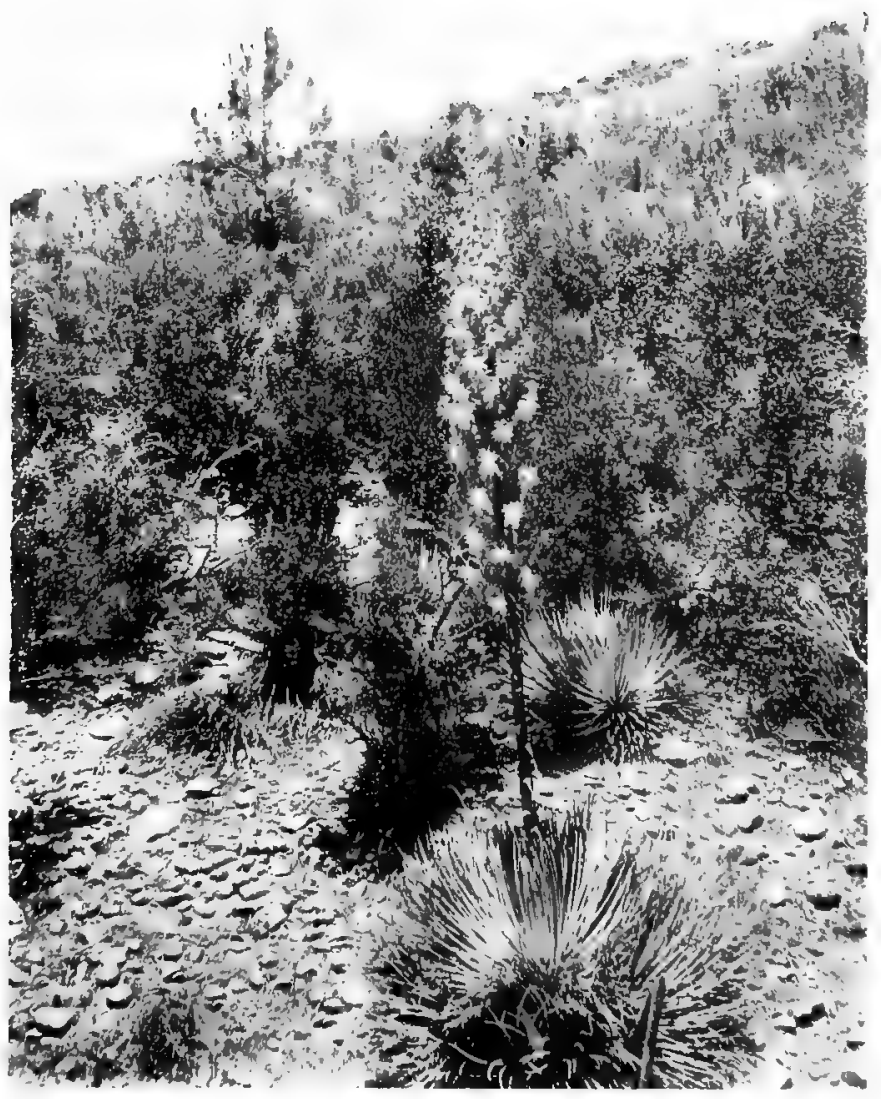

A Yucca in the Chaparral 

be separated here and there. Indeed, it is often most interesting when interrupted by large granite boulders and jumbles of rocks, with the clean gray shade of which it forms a fine contrast on a clear morning.

If we look still farther up toward some higher slopes, miles away, we shall see only a uniform and continuous stretch of low brush that appears at that great distance hardly otherwise than a green pasture clothing the barren mountain. As we walk toward it the bluish-green changes to a bronzegreen, and then suddenly we recognize the broad sweep of chemisal, with a few scattered scrubby oaks and mountain mahogany in between.

In the account of forest embellishment should be included those hum- 


\section{FOREST TREES AND FOREST SCENERY}

blest plants, the liverworts and mosses and the lichens that so beautifully stain the rocks and color the stems of trees. A close study of all their delicate and tender characters, both of form and color, is always a revelation. Among these lowlier plants it is no uncommon sight in the depth of winter to see a field of fern sending a thousand elegant sprays through the light snow-covering; or half a dozen kinds of mosses, all of different green, but every one pure and brilliant, gleaming in the shadow of some dripping rock. Between the rock and its ice cap, covered by the latter but not concealed from view, there is a fine collection of the most delicate little liverworts and grasses, herbs with tender leaves, and even flowers, it may 
be, on some earthy speck where the sun has melted the ice - all as if held in cold crystal.

A word also remains to be said about the vines and creepers. As far north as Pennsylvania, and even to the States bordering the Great Lakes, these clambering plants are a conspicuous element in the forest. Virginia creeper, clematis, the hairy-looking poison oak, and the wild grape, are among those that are most familiar. In the woods of the lower Mississippi Valley the wild grapevines often make a strange tangle among the old and twisted trees and hang in long festoons from the boughs. They are not uncommon in some of the northerly States, though less rank and exuberant in growth. 
The common ivy is one of the most beautiful of all creepers. It makes a fine setting for the little wood flowers that peep from its leaves. I like it best, however, where it clings to some old oak or other tree and brings out the contrast between its own passiveness and weakness and the strength of the column that gives it support. 


\section{III}

\section{DISTRIBUTION OF AMERICAN FORESTS}

THE geographical distribution of 1 trees has been referred to occasionally in the preceding chapters. This distribution, gradually accomplished during the progress of ages, has not been accidental; on the contrary, it has been due to natural causes, and arises out of the special needs and adaptations of each species. The geology of a region, which determines in many respects the character of the physical forces of both the earth and the air, is no small factor in the development 83 


\section{FOREST TREES AND FOREST SCENERY}

of the forest. The character of the climate, the nature of the soil, the degree of moisture in the soil and in the atmosphere, the amount and intensity of the sunlight - in short, the various elements and natural forces that constitute the environment of a tree - are the all-important conditions of its life. On these it depends, and according to its own peculiar nature and its special needs, selects its natural home.

Yet the manner in which this selection is accomplished, though simple in theory, is complicated by many circumstances. Frost, fire, insects, and floods, by destroying the trees or their seeds, may retard the progress of the species. The wind may be unfavorable. The seeds hang upon the trees ready and ripe for germination, but a breeze comes 
along and carries them to a place where the conditions are ill adapted to their peculiar nature. The following year the wind is propitious and the little trees soon start into life. But presently the seeds of another tree, whose growth is by nature faster, are conveyed to the same spot, and the intruders outstrip the others in rapidity of growth and spread a canopy of foliage that screens the smaller trees from the life-giving sun and dooms them to destruction. Thus only a few of the numberless seeds that are produced each year live, and fewer still are able to maintain or extend the boundaries of the parent tree. Sometimes, too, the frugality or hardiness of a species may be the reason for its exclusive occupation of a certain locality, since other trees may 
FOREST TREES AND FOREST SCENERY

find it impossible to live at high altitudes and on rocky ridges or to subsist upon rough, poor soil. Consequently we shall find some kinds of trees exclusive, gregarious only among themselves, while others mingle freely in the general concourse.

Through the persistency, therefore, of the vital forces of nature, through a suitable climate or situation, through the power of adaptation and the delicate adjustment of many details, the vast armies of trees, like migratory races, have at last accomplished their purpose and found their several homes; and to us the varied aspect of the forests, as we traverse the extended territory of our country, is in a manner explained. There are stretches of land over which the tree growth is dense 86 
and uniform; where the forest is given over, it may be, almost entirely to a single kind of tree. In other places the trees may join in varied luxuriance, young and old, familiar and strange, on some fertile, protected plain or well watered mountain side. In still other places they may be seen struggling up the steep slopes and maintaining a precarious existence on bleak, rocky ridges.

While the eastern portion of the United States is, generally speaking, the home of the broadleaf species, and the northern and western portions are similarly occupied by the coniferous forests, these areas may readily be subdivided into specified regions of distinct forest growth. The latter, however, cannot be accurately delimited, since 
the regions naturally penetrate into one another and overlap, on account of the manner in which forests have extended their bounds.

In the basin of the Great Lakes, where the glaciers of a recent geological age have prepared a light, loose, gravelly or sandy soil, the white pine belt extends through the States of Minnesota, Wisconsin, and Michigan, and penetrates into portions of Pennsylvania, New York, and New England. Once covered with dense tall forests of white pine, interspersed in places with other northern conifers, or broken by smaller areas of broadleaf forests, the white pine belt has now yielded to us its richest treasures. The exacting demands of our modern artificial civilization have drawn ceaselessly upon 
these resources, and the assiduous ax and the fire that follows in its train have invaded even the most secluded regions. The resulting barren spaces, where they have not become cultivated land, have either reverted to the young white pine itself or have been transformed into oak barrens and open forests of broadleaf trees. Thus the aspect of the region has been altered, though many a limited spot may be found in which the tall majesty of the primeval forest still finds its full expression.

Extending from southern New England along the entire range of the Appalachians, sloping toward the Atlantic, and spreading far westward to the Mississippi and beyond, the region of the eastern broadleaf forests covers 
a vast territory. Not that the conifers are here entirely absent, for several of these, including the white pine itself, follow the mountain ranges and scatter throughout the hills and plains; but their number dwindles in the proportion of the whole.

Beyond this region to the southward, in the States that border the Gulf east of the Mississippi, in Georgia, and stretching along the coast northward, a region of pines is once more encountered. This section of our forests, though it has already yielded generous supplies, is among the richest in the country. From the pineries of the South is obtained much of our construction timber; and thence, too, we derive our pitch, tar, and turpentine from the sap of the trees. 
Finally, within the eastern forests a restricted region at the southern end of Florida, including the Keys, may properly be separated from the rest. For here is found a distinctively tropical vegetation, differing entirely in character from the forest flora to the north. Many trees indigenous to the West India Islands have established themselves upon this small area, on which the number of species exceeds that of any region of equal extent within the United States, not excepting even the varied forest growth of the Mexican border line, to which alone it might be worthily compared.

Separating the forest floras of the western and eastern United States, lies the broad region of prairies and plains. Though trees are found for the greater 91 
part only along the banks of streams, this region has a curious interest for the forester. It is believed by many that this wide country, now waving in grain and grass and covered with extensive farms, was at one time enriched with scattered forests; but that these have disappeared under the ravages of repeated fires, kindled, it is supposed, chiefly by the Indians. At present our own race is perseveringly reclothing these prairie lands with groves and avenues of trees, and is planting belts of them about farms and orchards for protection from hot or frosty winds. Thus the fringed borders of the streams are widening. The outcome of this activity is a development that stands in marked contrast with the hurried consumption of our other forests. 
Then, lastly, there lies beyond this region the vast territory of the Rockies and the ranges of the Pacific coast. Extending over so great a part of our country, the forests of this region exhibit many transitions that reveal the intimate relations between trees and their natural environment; yet here we cannot but notice the enormous preponderance of the coniferous over the broadleaf trees. Indeed, it amounts almost to an exclusion of the latter; for, while some of the poplars and willows and several species of oaks and a few maples are indigenous to this part of the country, the last two in particular to portions of California, other broadleaf trees are mere stragglers in the land.

The forests of the West retain much 
more of the flavor of wildness than do those of the East, though they likewise show many evidences of the hand of man. It is true that paths and roads lead from many familiar resorts into these mountain forests, that there are signs of the lumber industry and of fires, and that there are large barren areas where sheep have been continuously driven for pasture. Extensive as this interference with original conditions has been, however, the changed aspect of the forest has not always remained permanent, because nature, where it is possible, comes back patiently to restore life and beauty to the wasted places. Over lofty ranges and in inaccessible places we may still find the original forest bequeathed to us from early days; but not in such places

94 
only: for if we look closely we shall also recognize the old character and expression in the harvested forests that have long since been deserted and forgotten and at last returned, like lost children, to the fostering care of their mother.

The forests of the West may be fitly separated into two parts. The greater part embraces the Rocky Mountain ranges, while the other extends from the crests of the Sierra Nevada to the sea. In the former the forests are sometimes open in character and separated by parks or grassy plains, or they constitute a scattered tree growth on the high altitudes of the rougher ridges. This open character is sometimes due to devastation by fires, but generally it is the result of climatic conditions. And yet there are wide tracts and 
spaces within this region that bear dense forests, notwithstanding the barren soil and the austere climate; forests that have been but little or in no wise disturbed, and whose expression differs in an unmistakable manner from the opener growth of the broadleaf forests of the East.

Denser than these and more aweinspiring are the forests of the States bordering the Pacific. Here the moisture from the sea, an equable climate, and a generous soil, have produced the tall and somber red firs, the stately hemlocks and cedars, the redwoods of the coast, and the consummate beauty and magnificence of those opener groves of big trees, sugar pines, and bull pines, that have always commanded the admiration and wonder of visitors to that region. 


\section{IV}

CHARACTER OF THE BROADLEAF FORESTS

TF the individual trees of the two

1 main groups that were described in the opening chapter impress us differently as they belong to the one or the other, it will be found that the two kinds of forests likewise convey dis tinct impressions. Different in aspect, they are also distinguished one from the other by the different atmosphere or spirit that pervades them. Taking leave here of the trees as individuals, I shall now examine the characteristics of woodland scenery.

97 
It has been said that the broadleaf trees grow naturally over a wide extent of territory. Of the unbroken wildernesses that covered the eastern parts of our country when it began to be colonized, only fragments remain. A few States are still densely wooded, but in these the forces which have caused the disappearance of similar forests in other regions have now begun to assert themselves. Some will yield to their old enemy, the ravaging fire that could so often be prevented; others must ultimately recede to make way for agriculture; many will be removed more rapidly for the sake of their material. It is confidently to be expected, however, in view of the widening influence forestry is exerting, that where it is desirable a provision will be 98 
made for a future growth to replace the present one.

Of the broadleaf forests there are many types. There are forests of oak and chestnut, of maple and beech; dry upland forests, and the tangled woods of the swamps. There are young thickets of birch and aspen, of willow and alder, and scrubby oak barrens. There are second-growth forests, and now and then even a patch of fine old virgin timber. In size, also, there is a great difference, from the grove that covers the hilltop to the unbroken forest that stretches over an entire mountain range.

It appears, therefore, that variety is one of the marked characteristics of our eastern woods. As several hundred different kinds of trees enter into 
FOREST TREES AND FOREST SCENERY

their composition under every form and modification of circumstance, we find in these woods an endless novelty and perennial freshness. The young swamp growth of red maple, white birch, and alder, bedded in grass and wild flowers, is very different from the dense young forest of birch and aspen of the northern woods that, under the influence of ample light, has sprung into being after some recent fire, the signs of which are still visible in the charred stumps under the young trees. The open groves of old oak and chestnut on the hill, with the slanting light of autumn and deep beds of dry, rustling leaves, are likewise different from the secluded forest in unfrequented mountains, where young and old growth mingle together: crooked ashes and 
moss-covered elms with straight young hickories, with shrubs and vines, and little seedlings sprouting among the rocks and mosses.

If we were to proceed in a continuous journey from the staid forests of the North to the more diversified growth of the intermediate States, and, going on, were to visit the complex forests of the South, we should notice only a very gradual transition. Yet if we were to study any particular region within these larger areas it would be found to have certain definite characteristics.

Let us imagine ourselves standing, for instance, on some point of vantage in the Blue Ridge of Virginia, the season being early May. The view extends across ranges of low, 
rounded mountains, which are fresh with the new foliage of spring. On the nearest hills the individual trees and their combinations into groups can be distinguished; but receding into the valleys and more distant slopes the forms and colors grow less distinct, till the tone becomes darker and at last melts into the familiar hazy blue of the distant hills. Looking again at the nearer hillsides, we recognize the tulip trees with their shapely crowns, clothed in a soft green and lifted somewhat above the general outline. The light green of the opening elms and sweet gums can be very well distinguished beyond the more shadowy beeches, ashes, and maples. The remaining spaces are occupied by hickories and chestnuts, still brown and leafless, and 
by rusty-hued oaks, which are only just beginning to break their buds. Within the leafless portions of the wood an occasional dash of bright yellow or creamy white, not quite concealed, shows where the sassafras or dogwood is in bloom. The crests and ridges, however, are likely to be occupied by groups and bands of pines, while the sides of the mountain brook will be studded with cedars and hemlocks.

In such scenery, if it be natural, there is no vulgarity and no faultiness of design. With all the variety there is still a fitness in form, color, and expression. It is rough, but pure in taste. For instance, the pine groves on the mountain ridges are not sharply defined in their margins and thus separated from the rest of the forest, but 
they gradually merge with the neighboring trees in a way that was naturally foreshadowed in the conformation of the land and the composition of the soil.

A feature so natural and self-evident may hardly appear worthy of notice; but its value is appreciated as soon as we compare the outlines referred to with the rigid forms of some of the artificial forests of Europe. Those who have seen the checkered forests of Germany, where the design of the planted strip of trees, like a patch upon the mountain, is unmistakable, will readily note the contrast between the natural and the artificial type. Neither is there any striving for effect in the natural forest, an error not uncommon in the tree groupings of parks or private estates. In these an effort 
is sometimes made to produce an impression by contrasts in form and color, but too often the outcome is mere conspicuousness; while nature, in some subtle way, has touched the true chord.

Forest scenery, however, need not be as extensive as this in order to add appreciably to the beauty of landscape. In the valley of southern Virginia, among the peach orchards and sheep farms, low hills lie scattered on both sides of the valley road. The mountain ranges beyond them recede to a great distance, and are partly hidden from view by these intervening hills. The latter, however, are decked with bits of woodland: groves of oak, chestnut, and beech, where the horseman on sunny summer days finds a welcome coolness and shade. Would these sylvan spots 


\section{FOREST TREES AND FOREST SCENERY}

be missed if they were to be removed? They now exercise a beneficial influence on the drainage and moisture conditions of the surrounding farmlands, and they supply some of the home wants of the farmers. But they have an esthetic value also. They are usually in neat and healthy condition, and, viewed either from within or without, they are balm to the eyes as they lie scattered promiscuously over the hills.

It is hardly two hundred miles by road from that region to the high mountains of the North Carolina and Tennessee border, where we find broadleaf forests of the wildest and roughest kind. These happily still possess the great charm of undisturbed nature. The small mountain towns lie scat- 
tered far apart. The region is even bleak and dreary - at least until the summer comes; but when everything turns green the season is glorious. As we ride through these woods we realize the majesty of their stillness and strength, and cannot help admiring the great oaks and chestnuts that contend for the ground, succumbing only after centuries in the strife.

While the broadleaf forests of western North Carolina and eastern Tennessee are characterized principally by grandeur, this is not commonly a pronounced trait of the leafy forests. Rather are they distinguished for a certain air of cheerfulness, the expression of which will vary in different localities; but in some way it will manifest itself almost everywhere. 
Thus, in the southern half of $\mathrm{New}$ England woodland scenery is marked by a peculiar expression of quiet gladness. Whether it be in small farm woods among low hills, or in continuous forest, as in the Berkshires, there is the same happy choice in bright and cheerful trees: maples, birches, elms, and others; some bright with early spring blossoms, some adding to the variety of color by their bark or shining leaves, others agile of leaf and bough in the frequent breezes. Here we find an abundance of oaks, trees whose fresh, glossy leaves seem to be specially well fitted to purify the air, for there is a distinct and refreshing odor in oak forests. We find an ample choice of tender, springy plants among the moist rocks. These smaller 


\section{CHARACTER OF BROADLEAF FORESTS}

woods, too, are the favored haunts of the songbirds, for here they find the glint of sunshine that they so much delight in.

A similar warmth of expression belongs to the leafy woods of other regions. If we compare New England with Pennsylvania, we shall find that the broadleaf forests of the latter are denser and more continuous, while they are at the same time richer in the variety of trees, shrubs, and other forms of embellishment, which find here a milder air and a richer soil. Springtime is more luxuriant and replete with happy surprise and change. But while these forests are perhaps more elaborate than those of southern New England, I cannot say that they impress me as being so homelike and engaging. 
FOREST TREES AND FOREST SCENERY

Along the Gulf and in Florida the dank forests of the swamps and river bottoms, finding all the conditions favorable to a luxuriant vegetation, are characterized by extraordinary complexity of growth. Perhaps we enter some secluded patch of virgin forest, and sit down for a while in its dense shade, impressed by the strangeness and solitude of the place. Our curiosity is aroused by the multifarious assemblage of trees, vines, and shrubbery, and we wonder how many ages it has been thus, and how far back some of the oldest trees may date in their history. But they seem rather to have no age at all; only to be linked in some mysterious way with the dim past out of which they have arisen.

A mighty live oak leans across the 


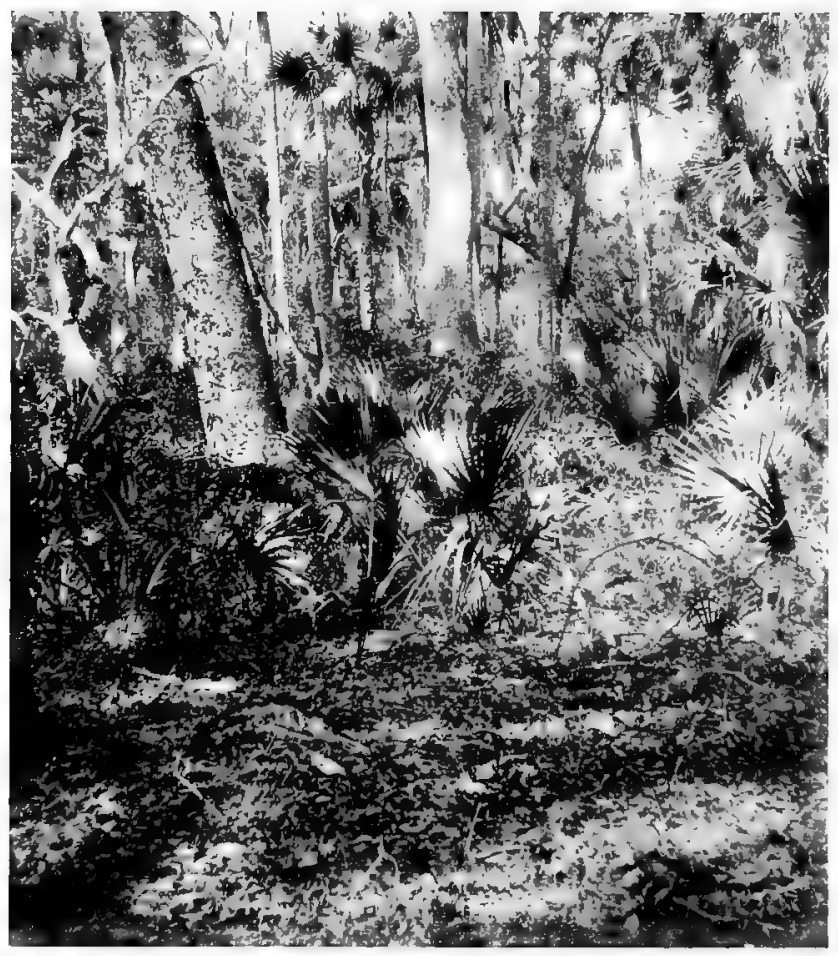

Virgin Forest Scene in Florida 

scene, moist and green with moss; another is noticed farther away among slender palmettos, whose spear-edged leaves catch the sunlight. Vines and climbers hang about the stems or droop lazily from the boughs. In the nearby sluggish water, where the soil is deep and moldy, stands a sweet gum with curiously chiseled bark, as if some patient artist had been at work; and a little beyond, some cypresses are roofed by the delicate web of their own foliage.

We may sit dreaming away a full hour thus, with only the hum of a few insects and perhaps a stray scarlet tanager flitting by to disturb our meditations.

It has been indicated in a former chapter that the broadleaf woods, 
taken as a whole, are decidedly richer in shrubs and small plants than the evergreen or coniferous forests. This adventitious source of beauty has much to do with their general character, because the gay show of blossom and fruit, bright stem, and diverse habits of growth of these lesser plants, contributes appreciably to the liveliness of sylvan scenery. But the effect derived from the blossoms and fruits of many of the trees themselves should not be overlooked. In this respect the broadleaf trees are superior to the evergreens. The poplars and willows ripen their woolly and silvery tassels when the snow has scarcely disappeared. The bright tufts of the red maple, the little yellow flowers of the sassafras, the snowy white ones of the serviceberry 
and flowering dogwood, the latter's red berries in fall, the brilliant fruit of the mountain ash, the perfect flowers of the magnolias, the heavily clustered locusts, honey locusts, and black cherries, and the basswoods with fragrant little creamy flowers, alike do their part in lending character to the forest wherever they may have their range.

Then, in addition to the beauty that appeals to us through the outward senses, there is a quality in the forests that is dear to us through an inward sense. It is the influence of a temperament that seems to belong to the place itself: the pure and health-giving atmosphere, the quiet and rest that binds up the wounded spirit and brings peace to the troubled mind. 
We leave the turmoil of the city and the thousand little cares of daily life and seek refuge for a while in sylvan retreats, in some pleasant leafy forest with murmuring water and sunbeams; and presently the ruffled concerns of yesterday are smoothed away and the forest, like sleep, "knits up the raveled sleeve of care."

In the woods there is harmony in all things; all things are subordinated to one purpose and desire: that the best may be made out of life, however small the means. There is a kind of honesty and truth here, and a self-sufficiency in everything. Shakspere says, in the words of Duke Senior, who stands surrounded by his followers in the Forest of Arden ("As You Like it," act ii, scene 1) :- 
Are not these woods

More free from peril than the envions court?

Here feel we but the penalty of Adam, The seasons' difference; as, the icy fang And churlish chiding of the winter's wind, Which, when it bites and blows upon my body,

Even till I shrink with cold, I smile, and say,

"This is no flattery : these are counselors

That feelingly persuade me what I am."

* * * * * * *

And this our life, exempt from public haunt,

Finds tongues in trees, books in the running brooks,

Sermons in stones, and good in everything. 


\section{V \\ THE CONIFEROUS FORESTS}

TT has already been said (page 31)

1 that the evergreen or coniferous forests differ from those described in the foregoing chapter by a denser community of growth and by their frequent occurrence as "pure" forests. Their gregariousness makes it proper to apply such expressions as the "pine forests of Michigan" and the "spruce forests of Maine." It will be seen presently that these special characteristics are esthetically important. Moreover, it is a fact that they borrow much grandeur and beauty from the atmospheric con- 


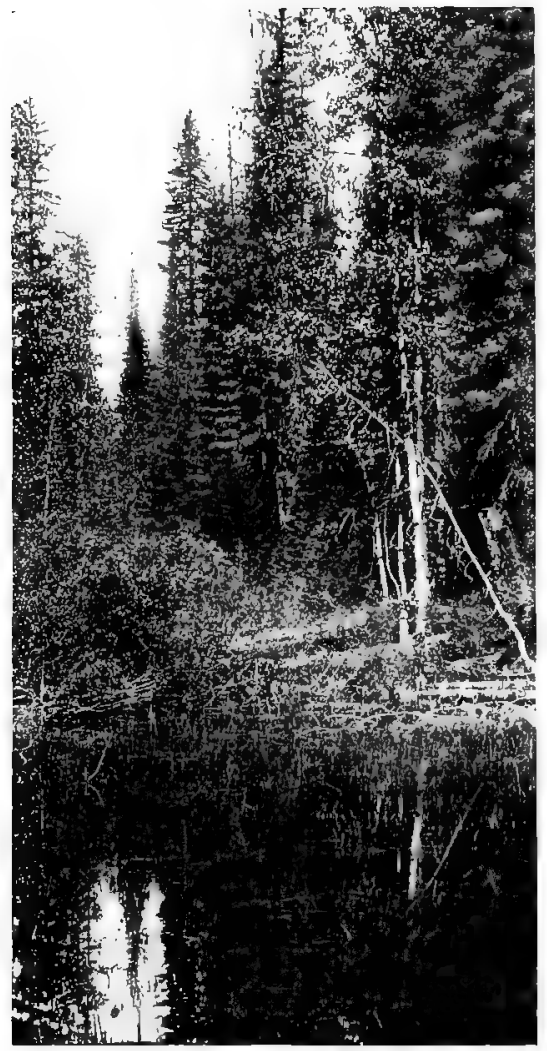

Courtesy of the Burea of Forestry

A Group of Conifers. Montana 

ditions of their environment, which, if we except certain large tracts of pine forests, is commonly placed among mountains and at considerable elevations above the sea. To these several sources must be ascribed many of the qualities that have invested the evergreen forests with a peculiar magnificence and beauty.

The reader may be surprised at the statement that coniferous forests are distinguished for a "dense community of growth," for it must have been noticed that many of our Rocky Mountain forests do not bear evidence of this fact. And yet it is true that the typical habit, so to speak, of the conifers is a close huddling together of individuals. It is shown in the massive red fir forests of western Wash- 
ington and the redwoods of California, which are probably the densest and heaviest in the world; in the crowded Engelmann spruce and alpine fir groves common to certain soils and situations in Colorado; and in the dense tracts of lodgepole pine scattered throughout the mountains of the West. In the East the same tendency is illustrated by the better sections of the Adirondack spruce forests and the splendid pineries that once covered the Great Lake region. If we call to mind these extensive examples, we realize how the conifers ever strive to build a dense and impenetrable forest. That they are capable of a like growth in other parts of the world also, will be attested by those who have seen the spruce and fir forests of Germany and France. 


\section{THE CONIFEROUS FORESTS}

While the regions that have just been mentioned exhibit the health and vigor of coniferous forests under favorable natural conditions, there are certain portions of the Rocky Mountains where the climate is too dry and the topography and soil are too austere and rocky to suit even that hardy class of trees. So here, under circumstances that may almost be pronounced abnormal for forest growth, the evergreens fight a harder battle, while the broadleaf trees, with the exception of the poplar tribe, are scarce indeed. We must, therefore, turn to the more typical coniferous forests that have enjoyed at least a fair share of nature's gifts - whether it be within the range of the Rocky Mountains or elsewhere - to understand those peculiar quali- 
ties that are connected with their surroundings or their characteristic habits of growth.

One of the commonest attributes of such forests is their grandeur; partly inherent and in part also derived from the sublimity of their surroundings. Their situation is often in the midst of wild and picturesque mountain scenery, where they find a proper setting for their own majestic forms among crags and precipices and on the great shoulders of mountains; where powerful winds and severe snows test their endurance and strength. It is here that we chiefly find those awe-inspiring distant views that harmonize so well with the evergreen forests. The trees spread over the mountains for miles and miles in closely fledged masses, and become 


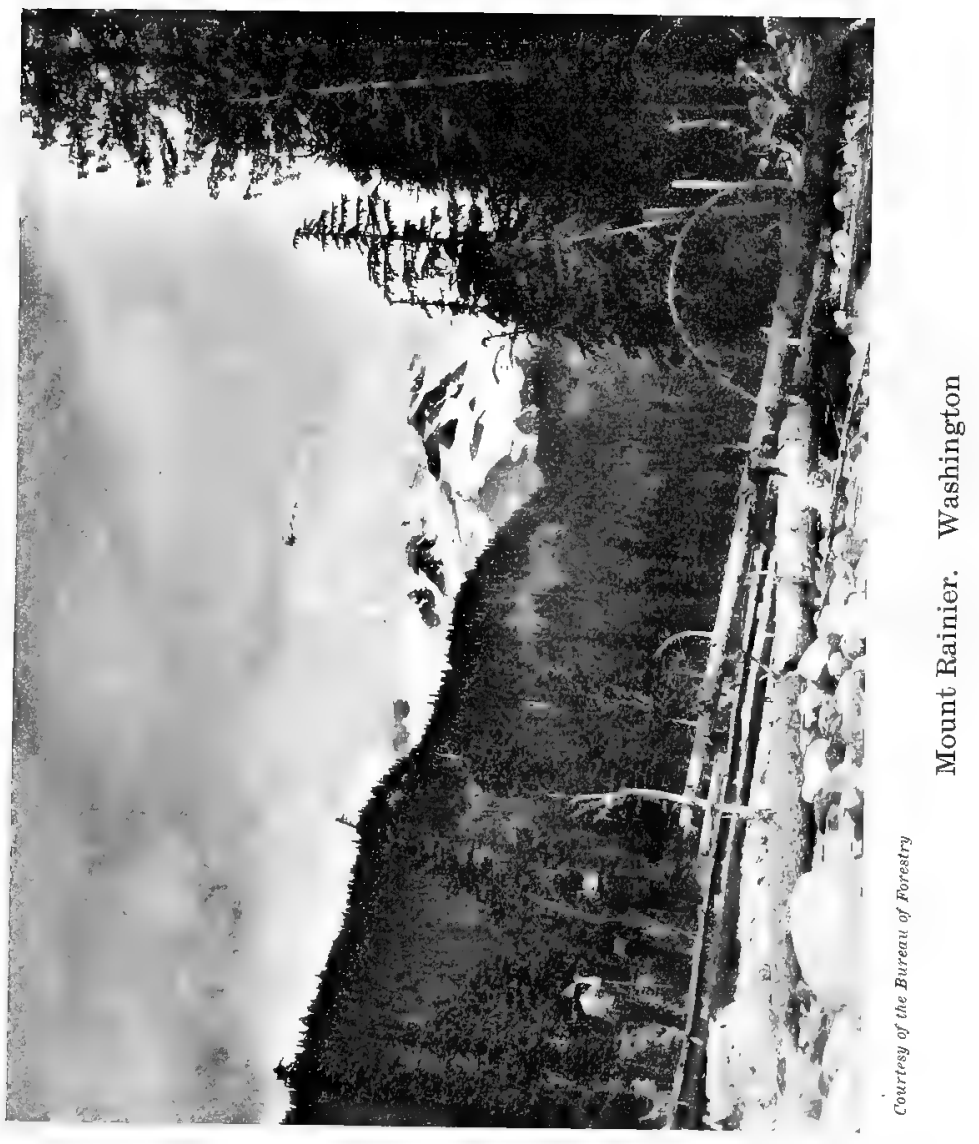





\section{THE CONIFEROUS FORESTS}

more impressive with distance as the color changes from a continuity of dark green to shades of blue and soft, distant purple. In form and color the trees blend together and seem to move up the dangerous slopes and difficult passes in mighty multitudes.

Contributing to the same impression of grandeur, we have the possibility in these lofty regions of certain glorious effects in sunlight and shade. At sunrise the first rays flash on the pointed tops of the uppermost trees, and with the advancing hours descend the dark slopes on their golden errand. Meanwhile the western sides lie in shadow. At noon a soft haze spreads through the valleys, and in the twilight hours the intense depth of purple in the distant ranges, where stratus clouds catch 


\section{FOREST TREES AND FOREST SCENERY}

the last rays of the sun, obscures the contours of the forests and makes them even more sublime. This, too, were not possible without great mass and uniformity of aspect.

The interchange between lights and shadows cast by the moving clouds is nowhere so effectively exhibited as in higher altitudes and over the surfaces of evergreen forests. A wide expanse enables us to follow with our eyes the interesting chase of the cloud shadows, as they fly up the slopes, the steeper the faster, and glide noiselessly but swiftly over outstretched areas of endless green. The clouds seem to move faster over mountain ranges, as a rule, than they do over the low valleys. Or is it only because now we see them nearer by and can gage the rapidity of their flight? 


\section{THE CONIFEROUS FORESTS}

Suppose, instead of a restless day, it should be calm, with cloud masses heaped in the sky and the sun sinking low. There has been a loose snowfall in the afternoon, and every twig, branch, and spray hangs muffled in snow. The rocks are capped with a light cover and ribbed with snowy lines along their sides. The air is pure and breathless. The disappearing sun sends back a rosy light to the canopy of clouds overhead, and the reflection falls upon masses of frosted, whitened evergreens, lending them a breath of color that deepens as the sun sinks lower still; and the rays enter the openings of the hills and flood the opposite slopes, till they glow with a fiery red.

Thus the grandeur of these forests 
may be due to expanse and volume, depth of color, sunlight and shade, or to effects borrowed from the clouds. Finally, we notice another kind of grandeur when coniferous forests are visited by storms. First comes the moaning of the wind, mysterious and unsearchable, and different from the roar and rush that sweeps through the broadleaf woods. Then follows the uneasy communication from tree to tree, a trembling that spreads from section to section. When the rush of the wind finally strikes the tall, straight forms they do not sway their arms about as wildly as do the maples, elms, or tulip trees, but bend and sway throughout their length and rock majestically.

Not in outward aspect alone are 



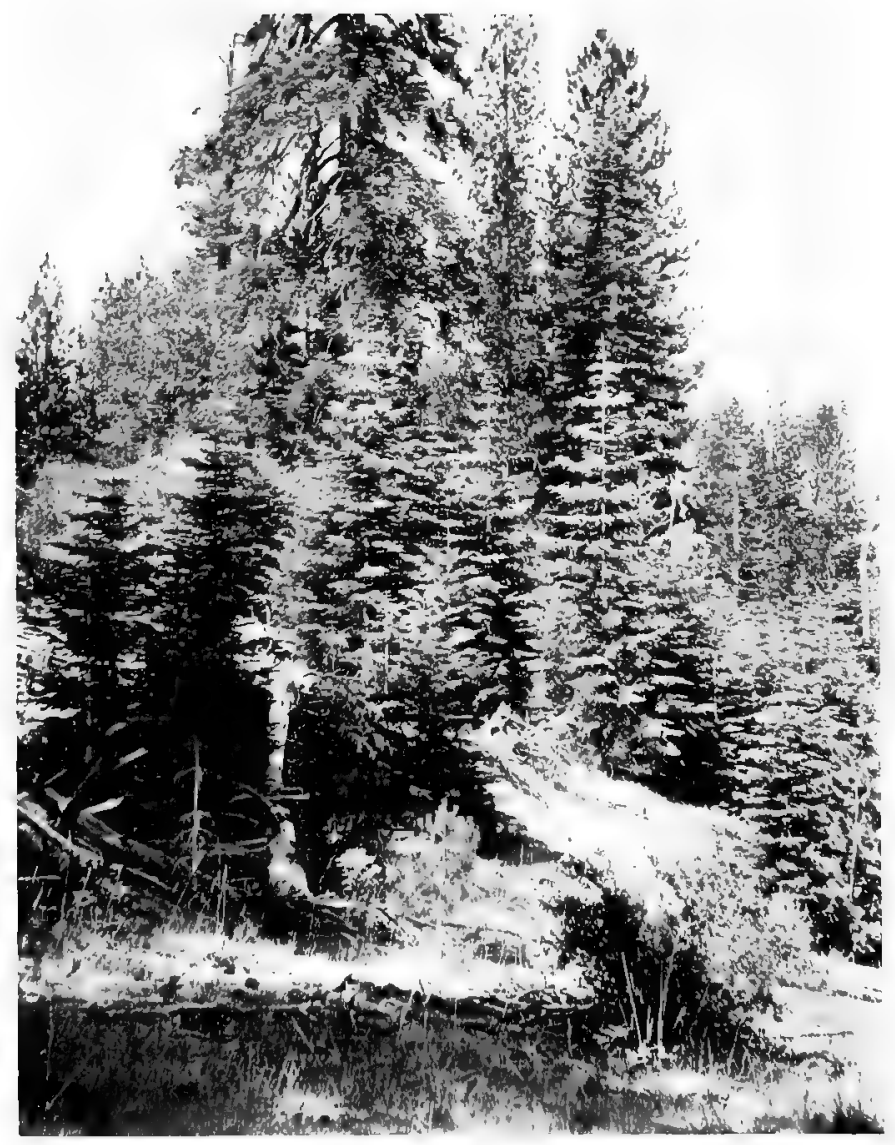

A Thicket of White Firs 


\section{THE CONIFEROUS FORESTS}

these forests noble and stately. A nobleness lies in the nature of the living trees themselves; for, though we may call them unconscious, it is life still, and they are expressive with meaning. Far simpler in their habits and requirements than the broadleaf trees, they are, nevertheless, more generous to man. Endurance and hardship is their lot, but noble form of trunk and crown and useful soft wood are the products of their life. There is no forest mantle like theirs to shield from the blast, especially when it is formed of young thickets of the simple but refined spruces and firs. When, at the last, they yield their life to man, it seems to me there is something exalted even in the manner of their fall. The tree hardly quivers 
under the blows of the ax; a mere trembling in the outermost twigs, and then, hardly as if cut off from the source of life, the tall, straight form sinks slowly to the earth.

Another common attribute of evergreen forests is their characteristic silence. Birds do not frequent them as much as the leafy forests. In these solitudes, far removed from village and farm, there is often no sound but the ring of the distant ax and the sough of the wind. In winter, as we push through the thickets of small spruces or hemlocks, or stand for a while beneath lofty pines, while all around is muffled in snow, the silence seems sanctified and vaster than elsewhere.

In addition to their grandeur and sublimity, and their silence, they are dis- 


\section{THE CONIFEROUS FORESTS}

tinguished for an element of softness. This is seen in the delicate texture and pure color of their foliage, the effect of which is heightened by being massed in the dense forest. We have already noticed the mild olive shade of the eastern white pine. When the wind blows through it, it seems as if the foliage were melting away. It would be difficult, also, to match the green color of the red fir, especially as it looks in winter; or the luxuriant bluishgray of the western blue spruce.

A further softening in the general effect of evergreen forests is produced by the manner in which the trees intermingle in the dense mass, merging their sharp, individual outlines in the rounded contours and upper surfaces of the combined view. Near at hand, of 
course, we cannot but notice the attenuated forms and jagged edges of the trees, which, indeed, are interesting enough in themselves; but on looking gradually into the distance we find them thatching into one another, closing up interstices and smoothing away irregularities in a remarkable way. This is particularly true of the spruces and firs; but in some of the opener pine forests, as, for example, in the longleaf pines of the South, the boughs and crowns themselves are rounded into masses and pleasing contours. It should be remembered, also, that these effects are present in winter as well as in summer.

The element of softness is sometimes brought into very beautiful association with certain effects of mists and clouds. 


\section{THE CONIFEROUS FORESTS}

The indistinct contours and delicate lights of the drifting vapors and cloud forms, as they wander across the trees, blend with the serene aspect of the forest. At other times the clouds gather into banks and lie motionless in some valley or rest like a veil upon the mountain tops. Wordsworth has d :scribed these effects in his graphic way by saying; -

Far-stretched beneath the many-tinted hills, A mighty waste of mist the valley fills, A solemn sea! whose billows wide around Stand motionless, to awful silence bound : Pines, on the coast, through mist their tops uprear

That like to leaning masts of stranded ships appear.

In spring or summer just before sunrise it is very beautiful to see how these 
banks of vapor are lifted by the stirring airs of the dawn, how the draperies of mist draw apart and open up vistas of the trees, which drip with moisture, and are presently illumined by the broad shafts of sunlight that pour down upon them.

Lest it be thought that only the dense coniferous forests possess superior qualities, I desire to put in a plea for the open ones also.

It is a universal truth in nature that when a living thing has made the best possible use of its environment, when the power within has been sacrificed and united to the circumstances without, there is evolved a dignity of character and a resulting expression of fitness and beauty. This principle is exemplified in the very open forests of the 


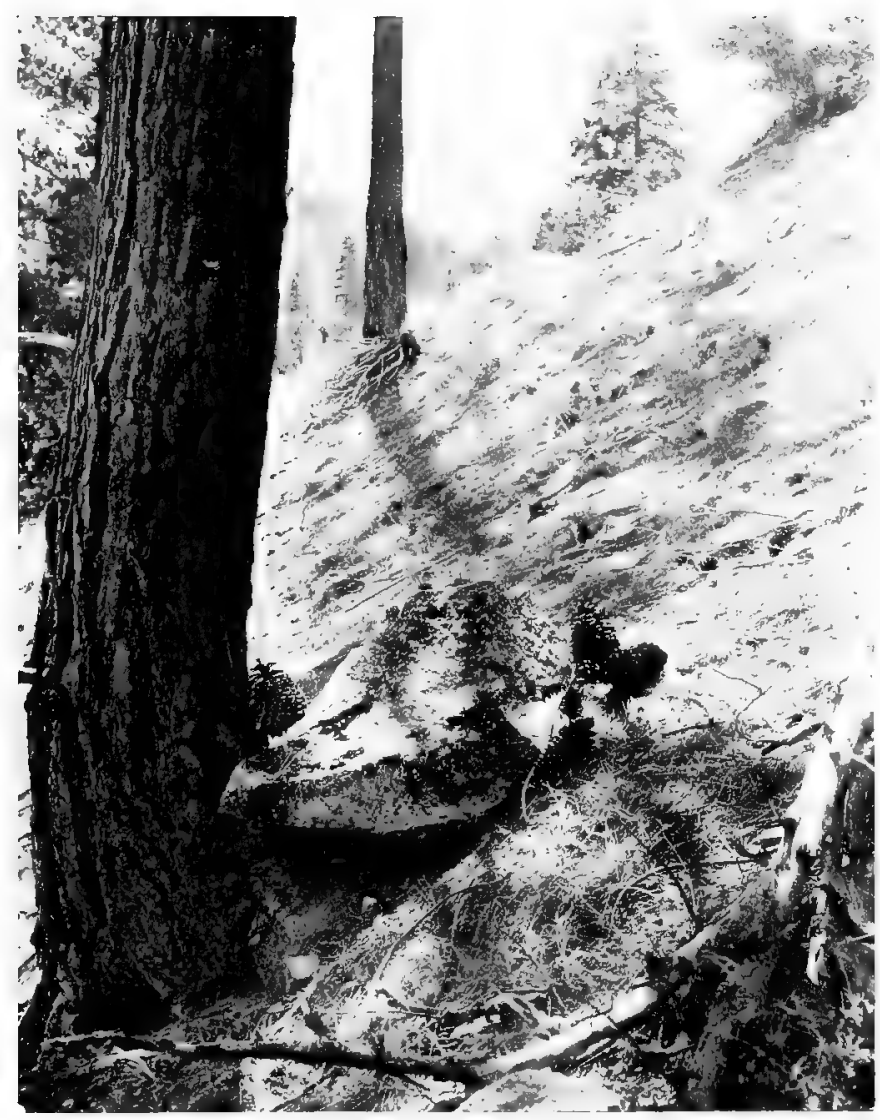

Courtesy of the Bureau of Forestry

An Open Forest in the Southwest 

Southwest. In the mountain ranges of New Mexico, Arizona, and southern California the forests have a hard struggle for existence. The winter months at the higher elevations are severe; in the summer rain is scarce, or entirely absent, and the sun beats down upon the dry earth through the rarefied atmosphere with intense and desiccating. power. Naturally the forest trees are scattered, and on the steep, crumbly slopes, dry and rocky, they hug the soil and cling to it with uncertain footing. But in a sheltered ravine, or on the back of a rounded ridge, or in a slight swale or hollow of the mountain - repeatedly, in fact, among those rugged slopes - we meet with the dignity, the beauty, and the peculiar expressiveness of the open coniferous forest, with 


\section{FOREST TREES AND FOREST SCENERY}

its fine definition and stereoscopic effects and the depth and perspective of its long vistas.

On the crest of the mountain, where, from the valley below, the early sunlight is first seen to break through, the trees, standing apart, do not appear so much like a forest as like a congregation of individuals, each with an identity of its own. Indeed, there among the fierce gales of autumn and winter each shapes its own life in a glorious independence, expressive in the knotty, twisted boles and the picturesque crowns. But in summer the breezes strain through the foliage with the lethargic sound of the ocean surge; or a halcyon stillness reigns under a deep blue, cloudless sky.

Large old trees, these, with a history, 


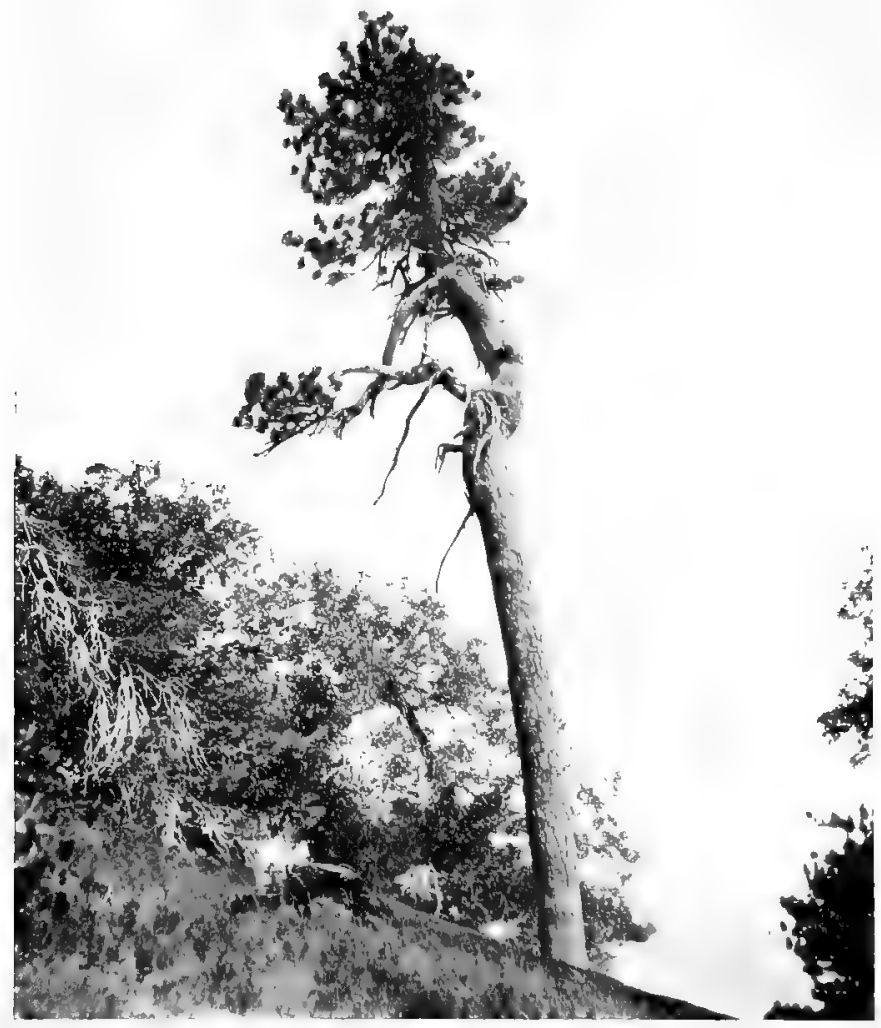

A Storm-beaten Veteran 

that have braved life together. They have seen companion veterans fall by their side, long ago, into the deep, closely matted needle-mold. Thence arose out of the moister hollows beneath the rotting trunk and boughs a new generation, and the greater number of these have disappeared, too, for some reason or another; only the strongest at last leading, to take the place of the departed. How dignified, how simple are these old, stalwart trees on the exposed ridge of the mountain.

Thus the coniferous forests, by virtue of their inherent qualities and by means of the effects they borrow from their environment, possess a tone that is as original and distinct as the character of the forests belonging to the 


\section{FOREST TREES AND FOREST SCENERY}

other class. It has already been intimated that the two are not always strictly separable, but that individual trees, or groups, or whole stretches of woods of the one will sometimes mingle with the other, a fact that has probably been noticed by the most casual observer. While the cone-bearers, however, not infrequently descend into the lower altitudes, the leafy forest trees are not so apt to be found at the high elevations at which many of the former find their natural home. Where the cone-bearers are merely an addition to the broadleaf woods they do not quite preserve their identity, but rather impress us as being merely a part in the general adornment and composition of the forest to which they belong. Where they remain 


\section{THE CONIFEROUS FORESTS}

"pure," however, as they do, for instance, in the pineries of the coastal plain in the South, they never fail to express, in one or another manner, their individuality as a forest; as by their uniformity in size and color, by their odor, or by the scenic character of the region of their occurrence.

All the preceding qualities of coniferous forests practically address themselves in some manner to our physical senses. But, like the broadleaf forests, these also possess a trait that rather addresses itself to our mood or personal temperament. A characteristic air of loneliness and wild seclusion belongs to them that contrasts strikingly with the cheerful tone of the other class. It has been commonly remarked that to some kinds of people 
FOREST TREES AND FOREST SCENERY

the coniferous forests are oppressive, at least on first acquaintance. Such natures feel the weight of their gloom and lose their own buoyancy of spirit if they stay too long within their confines; and it is noticeable that even the inhabitants of these lonely retreats are not infrequently affected with a reticence and a kind of melancholy that impresses the stranger almost like a feeling of resignation. This peculiar temperament, however, may be judged too hastily, and is understood better after a time. It is probably true that the familiar and accessible woods of valley and plain, where trails and wood-roads give us a feeling of security, are more attractive and agreeable to most of us; yet there is a wonderful charm about those dark forests of the mountains 


\section{THE CONIFEROUS FORESTS}

that have grown up in undisturbed simplicity. After the first feeling of strangeness wears off, as it soon will, they grow companionable and interesting. There is a virtue in the sturdy forms that have grown to maturity without aid or interference by man. We would not change them in that place for the most beautiful trees in a park. Even the woodsman, whose days are spent here in the hardest toil, feels a longing for the forest, his home, when his short respite in the summer is over. So we, too, though we may long for civilization after a few months in the forest, will yet feel the desire to return to it after once thoroughly making its acquaintance.

The attitude of the woodsman toward the forest is much like the af- 
fection which the sailor has for the ocean. There is, indeed, a similarity between their callings, and even the elements in which they pass their lives are not so dissimilar in reality as may appear on the surface. In his vast domain of evergreen trees that cover mountain and valley, the woodsman, too, is shut out from the busier haunts of men. He lives for months in his sequestered camp or cabin, where his bed is often only a narrow bunk of boughs or straw. His food is simple and his clothing rough and plain, to suit the conditions of his life. A large part of the time he is out in snow and rain, tramping over rough rock and soil. The camps that are scattered through the forest are to him like islands, where he can turn aside 
for food and rest when on some longer journey than usual.

Like the sailor he also has learned some of the secrets of nature. He does not usually possess a compass, but he can tell its points by more familiar signs: by the pendent tops of the hemlocks, which usually bend toward the east, or by the mossy sides of the trees, which are generally in the direction of the coolest and moistest quarter of the heavens. In an extreme case he will even mount one of the tallest of the trees to find his bearings in his oceanlike forest. If well judged, the sighing of the wind in the boughs, I have been told, says much about the coming weather; just as the sickly wash of the waves means something to the sailor. Withal, 


\section{FOREST TREES AND FOREST SCENERY}

both he and the woodsman are natural and generally honest fellows, hard workers at perilous callings, and less apt to speak than to commune with their own thoughts. 


\section{VI}

\section{THE ARTIFICIAL FORESTS OF EUROPE}

7 some of us, in this age of travel, 1 the forests of Europe have become as familiar as our own. As scenic objects they have their faults and their excellences. While we appreciate their order and neatness, and the beautiful effects that may arise out of the subordination of all components of the forest to one main purpose, we Americans always miss in them the freshness of nature.

These forests, as they now stand, are the result of a long-continued ap- 
plication of the scientific principles of forestry, under special conditions, to the European forests of old. Having referred repeatedly to forestry itself, I now purpose, to the extent which a single chapter will permit, to explain the sources of beauty, or the absence of it, in these artificial forests. I shall thus place in contrast with our own, which are just beginning to undergo a new process of development, those of Europe, which have long been subjected to one in many respects similar.

The importance of forests had long been understood by the people of Europe. The relation which they held to civilized life, both in a material way and otherwise, led, more than a century ago, to a systematic and scientific treatment. It was realized that these 


\section{ARTIFICIAL FORESTS OF EUROPE}

forests might be made perpetual, and so might furnish a constant supply of useful material; that they economized and regulated the flow of mountain streams, which are always of great importance to the agricultural lands of subjacent regions; that they held in place the loose soil of the slopes, thus averting avalanches and ruinous floods; that they broke the force of the winds, tempered and purified the air, and I may add, inspired man with better and happier thoughts.

For these reasons the people of Europe determined to guard their forests well, and to aid nature, if possible, in becoming still more useful to man. To this end they made a careful study of the life history of the forest, and investigated the requirements of the 


\section{FOREST TREES AND FOREST SCENERY}

trees and their rates of growth under varying conditions of soil, heat, light, and moisture. They also studied the numerous dangers to which the forest is exposed, and invented means and established laws for its protection. In short, they effected an ingenious adjustment between the needs of the forest and the requirements of man, and in course of time laid the foundations for a new system that was destined to be of great importance to the economic interests of nations.

Many sciences were involved in the solution of these questions. With the progress in means and methods the aims and objects of the new profession gradually grew to be more and more clearly defined, and knowledge and experience ultimately evolved the 
new science of forestry. To the forester were finally intrusted the reëstablishment, protection and preservation, the improvement, the regulation, the management and administration, as well as the final cutting, of the forest.

Such interference with the work of nature ultimately affected its aspect. In the long life of the forest the changes were slow, but in course of time the stamp of artificiality was impressed upon it, and the imprint of nature's own countenance was taken away. To an American, if he has seen a little of our wildness, a great charm is wanting in the artificial forests of Europe. The sun does not seem to set naturally, but to hide behind roads and houses. It may be a lifelike and harmonious scene, but it does 
not speak as deeply and expressively as our wilder woods. The necessity of it is thrust upon you. It seems, at times, as if the free will and perfect liberty of the air and rain, of the wind, were wanting.

These forests are crossed by roads and are often divided into sections of distinct age, kind, and appearance. Shrubs, if any, are few. The deer's. track is known. The history of these trees is known and recorded, and even their doom is fixed for a near or distant day.

There is, however, another side to this question. Through their very design and fitness for an intended object the effects that are produced are often decidedly pleasing. What these effects are will now appear from an examina- 
tion of the four different types or classes that constitute at present the artificial forests of Europe.

The type of artificial forest that differs least from our own eastern woods is one that has received the name of "selection forest." It constitutes a transition to the more complex forms. As in our own case, trees of different kinds and of various sizes are intermingled in the forest; but the European forest has more uniformity than ours, and expresses a conceived purpose. This is readily explained by the fact that from the beginning of the new method the trees were never removed indiscriminately from the wooded area, but that a careful selection was made from time to time of certain kinds, according to size and 
usefulness. Useful material, however, was not the sole consideration. The cutting was intended also to improve the conditions of growth for the trees that remained standing, and to increase the proportion of the species that were most useful or desirable. Finally, by opening up the forest to a proper degree of sunlight, the way was prepared for the germination of seeds that might fall from the old trees, in order to provide early for a new generation in the forest.

It will be readily understood, I believe, that in course of time such a forest would betray to the eye a certain gradation in the sizes of the trees, and a fixed proportion in the number of those belonging to one or another species. To this extent the selection 


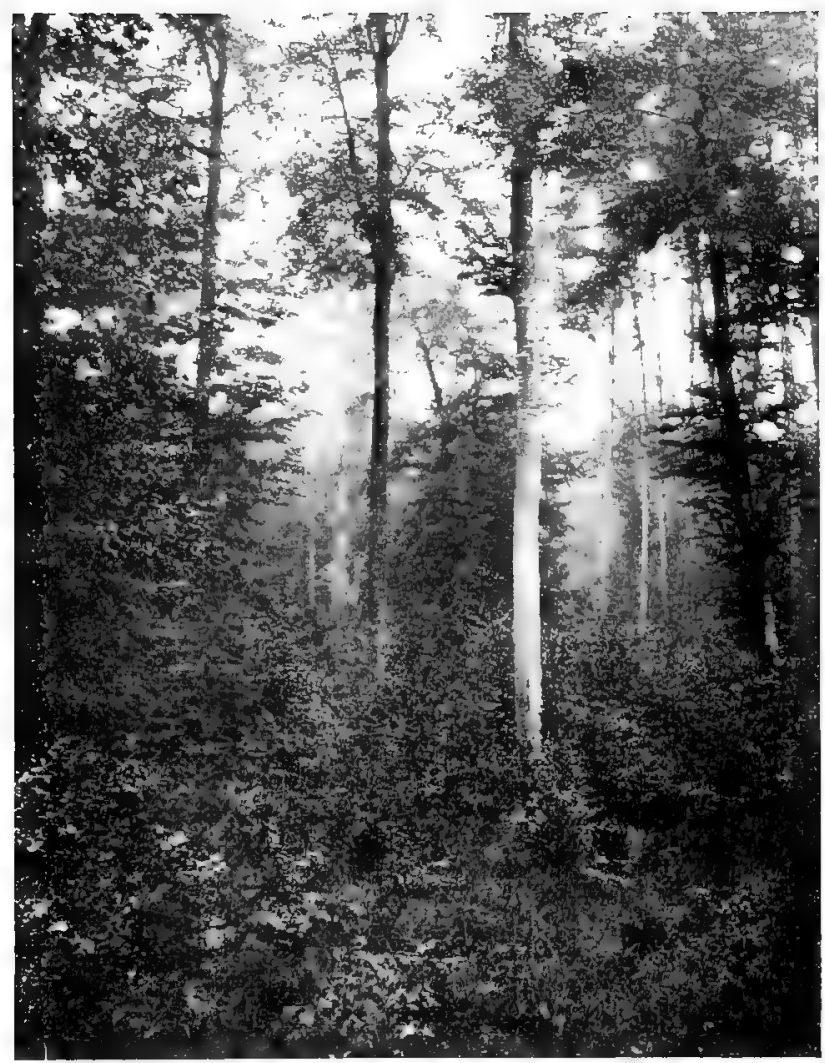

A German "Selection Forest" 



\section{ARTIFICIAL FORESTS OF EUROPE}

forests differ from our second-growth woods of the East; and yet, as compared to the other three European types, their principal merit, esthetically, is their naturalness. Though very different from our virgin forests, they nevertheless possess the variety, cheerfulness, and interesting play of light and shade that have been noted in an earlier chapter. In Germany they are usually somewhat precise and trim in appearance; but in France and elsewhere they look a little wilder, and are often enlivened with holly or ivy, some sportive raspberry, or other gay shrub or vine. In European countries where forestry has become thoroughly established this type of forest has gradually disappeared, or has diminished greatly in proportion, in order to make 
way for the other more highly developed forms.

The young forest growth that goes by the name of "coppice" is linked to the preceding kind by the association of time, for it is also one of the old forms. The sound of the word brings to mind the copses of England, those sportive little thickets that we may have read about, or seen running along the streams, or straggling over the hills. But the coppice of Germany or France is not quite the same as the copse of England. It is a young forest of businesslike aspect, in which a design for usefulness is unmistakable. The purpose in it is to reap an approximately equal harvest each year, such as firewood from beeches, hornbeams, or the like, withes from willows, charcoal from chestnut, or tanbark from oak. 
The means to accomplish the end are very simple. Only one kind of tree composes the coppice, and the forest is graded in sections, each a year older than the preceding. It is like a series of blocks, in which each is a little taller than the last. The tallest falls by the ax, and the next the following year, and so through the series till the cycle is completed, when it may be resumed as before. The repetition is possible because a tree is chosen for this kind of forest that will renew itself by naturally sprouting from the stump that is always left after cutting.

The coppice woods must be seen to appreciate their charm. They have a distinct flavor and a character that one easily remembers after a first acquaintance. Not too far removed from the town or village, yet often hidden in 



\section{ARTIFICIAL FORESTS OF EUROPE}

We have no coppice woods just like these in America. Our willow farms are the only ones that have been subjected to a system like the one described, and these are entirely too low to be called woods. They are graded in size and age from one to four years, and separated into blocks, just like the willow coppices of Germany. At a distance the lithe stems with diminutive tufts of foliage at the top, standing in straight rows, almost as dense as grain, have more the appearance of an agricultural product than a tree farm.

The Christmas tree plantations, a kind of forest gardening, as it were, remind us of the coppice in appearance, but cannot truly be called such. As the conifers that furnish us with 
Christmas trees are not capable of sprouting from the stump, the growers must depend upon planting for their propagation, which is a principle directly opposed to the idea of coppice.

Throughout the Eastern States there is an abundance of broadleaf stumpsprout thickets, which have come by inheritance to the ground from which their progenitors were removed by the wood-cutter's ax. While some of these approach nearly to the European coppices in intention, they do not bear out the resemblance sufficiently for a comparison. They lack their system and structure, though they depend upon the same power of reproduction for their existence. Nevertheless, they have their own charm. I remember one, at the edge of a tall forest, in 


\section{ARTIFICIAL FORESTS OF EUROPE}

which the sprouts were composed of oak, beech, hickory, tulip tree, dogwood, haw, and a few pine saplings, all of which formed a dense thicket of young trees. In summer it was pleasant to thread one's way through this place, quite concealed by the straight young growth, or to lie down there and listen for a whole morning to the twitterings and songs of birds, shut in by a wealth of foliage.

There is another type of European forest known as "coppice under standards." This is no more than a coppice growing underneath a selection forest somewhat different in aspect from the one already described. In the present case the selection forest is opener, the trees being fewer in number. Ample light is thus admitted for the growth of 
the coppice beneath. The appearance of the whole is that of an open forest into which the younger thickets have penetrated.

The esthetic effect of this combination may be described in very few words. While the coppice loses much of its charm, the overspreading forest gains something by this sacrifice. The former keeps the soil in fair and fresh condition, thus insuring a healthy growth to the large trees. It also shades the lower portions of their trunks, in consequence of which many of them develop into clean specimens, with strong, well-rounded stems, and graceful, wide-spreading crowns.

The last of the four types, the " high forest," is the most artificial and highly developed of the series. In its construc- 
tion it is in some respects like the coppice; for, as in that type, there is a uniformity of size in the trees on restricted areas, and the species that compose the entire forest are very limited in number. Coniferous high forests, which are the most common, are often composed of only a single kind of tree, and broadleaf forests of the same type rarely contain more than two or three species. These forests, like the coppice, comprise a full complement of sizes and ages, each confined to a separate section; but the steps are not single years, as in the coppice, but periods of ten or twenty years, or even more; so that the high forest, above all, is a much taller and older one. The sections that compose it are not regular in outline, ex- 
cept in certain forests on flats and levels, nor do they necessarily lie side by side in the consecutive order of size and age. Finally, the high forest also differs from the coppice in the manner of its origin; for, while the former owes its existence to seedlingss that have grown up spontaneously, or been sown or planted, the coppice is a young forest that has sprouted from the stumps of trees that have been cut.

Thus the high forest, while it may be compared with the coppice in its construction, is yet in certain respects so different from it as to convey a very distinct impression. I here disregard the younger portions of the forest, for, in the light of the present discussion, they are merely preparatory to the mature forest, destined to be useful 


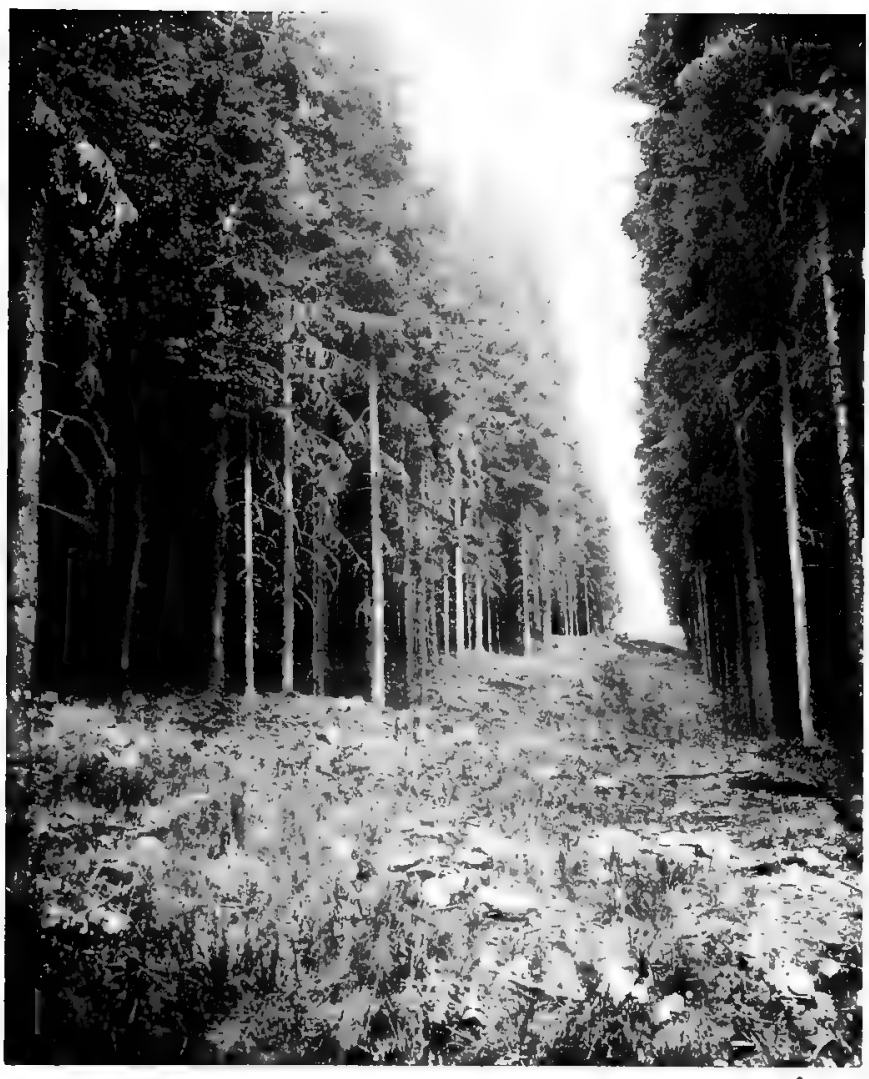

A "High Forest" of Spruce in Saxony 


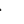




\section{ARTIFICIAL FORESTS OF EUROPE}

only after the completeness of age. In the older portions the one distinguishing characteristic is simple dignity. To this one quality all other points of excellence or beauty conform and adjust themselves. The young tree or the casual shrub that may have found its way into the company of the centenarians, is welcome; but the absorbing interest lies in the noble grandeur of the old trees that have grown up together. Some, under the influence of better soil or more light, have done better than others; but they are all sound and stately trees, and together represent the best product of the forest. Long ago other trees that grew in their midst, but were less promising, were removed for the sake of these. Under their continuous roof of foliage 
there is a cool, deep shade. The ground is scattered with fern, or covered with deep beds of leaves, or with the glossy needles of the conifers. If the forest has originated from seeds borne by a generation of trees that previously occupied the same spot, and the seeds germinated here and there and sprouted into a new forest upon the removal of the old, we shall now find the trees distributed in natural positions. Where, however, the new forest has been planted, which is often the case with the conifers, the trees stand in close rank and file, and we walk among their columns as in natural aisles and corridors. Here there is hardly a shrub to shut out the gloomy distance, and only at intervals a stray intruder with exceptional 
powers of shade endurance, a dwarfed yew tree, or a beech with refined, fanlike spray, comes into notice in the vista.

If these are some of the changes that are wrought in forests through the application of a new science, if, through forestry in Europe, one kind of beauty has passed away and another kind has been called forth, will our own forests, it may be asked, undergo in time similar alterations? We cannot doubt that they will grow more artificial; but under the modified application of the science of forestry to our own conditions, so different from those of Europe, the esthetic changes to be looked for would be difficult to predict. Nor would these 


\section{FOREST TREES AND FOREST SCENERY}

changes be predetermined, but, on the contrary, would depend very largely upon chance. It should be noted that forestry and landscape art are distinct; that the former, ordinarily, is not affected by the latter, and has its own ends and aims - those of material usefulness. I say ordinarily, because there are circumstances under which forestry might, with slight modifications and without a compromise to its own interests, adjust itself to some of the principles of landscape art. Indeed, this possible adjustment has been a subject of interest in Germany for more than twenty years, and the feasibility of a relationship between landscape art and forestry has been practically demonstrated by a noted German forester, Herr Heinrich von Salisch, on 
his own estates. This gentleman has applied to them the practical methods of approved forestry under such modifications as his experience and taste suggested, and has thereby not only made his forest profitable, but also more beautiful than it was before.

With respect to our own forests it may be asserted that most of the private forest holdings of the United States, and probably all our national forest reserves, ${ }^{8}$ as such, are destined primarily to serve purposes of utility, and very often to serve such purposes only. There are, however, a number of large forest estates owned by individuals, and some belonging to commonwealths and municipalities, which are esteemed as highly for their scenic character as for their material value, 
and pass in the public mind as emphatically under the name of parks as they occur to it in the light of financial investments. Such, for instance, are the Adirondack State Park and several large private forest estates in the same region, as well as certain large tracts of exceptionally beautiful forest in the western part of North Carolina and about the head waters of the Mississippi, which have now for some time attracted wide attention as desirable public possessions.

In such forests as these, esthetic considerations might suggest certain departures from the ordinary methods of forestry. Some people apparently wish to go further, and believe that certain portions of these tracts should remain entirely undisturbed, in order 164 
that their primeval character may be preserved for the enjoyment of all future generations.

The idea of a forest park, intact and inviolable, calls to mind our national parks of the West, which were actually established by Congress for that very purpose. Possessing, as they do, wonders of nature and exceptional scenery, these parks have been thought worthy of preservation solely for their own sakes. This difference in intention chiefly distinguishes them from the national reserves; so that, while the latter stand for the material benefit of the nation - whether it be directly, in the value of the timber, or indirectly, through the influence of the forest on the flow of streams - the value of the parks, on the other hand, speaks out of 
their own countenance. Their merit consists in the influence of beauty and sublime scenery on the moral state of man. They are healthful, vigorous breathing-places, where noise and smoke and harassing cares are laid aside.

It is well to bear this distinction in mind, because it appears not to be clearly recognized. While the reserves do not necessarily exclude some of the special advantages of the parks, their value lies, above all, in their stores of wealth. In this connection it may be said, for instance, that the designation "Adirondack Park," that is currently applied to the State forest of northern New York, is a somewhat misleading expression; for, although its beauty is well known and appreci166 


\section{ARTIFICIAL FORESTS OF EUROPE}

ated and the State Constitution at present even forbids any cutting within its limits, yet the most competent judges believe that the Adirondack forest is exceedingly well fitted for the purposes of practical forestry. Indeed, several private tracts within that region already constitute the best known examples of practical forestry in our country. If, however, it is intended to separate certain portions from the remainder, either within this region or that of the proposed Minnesota reserve, and to preserve these for their unique or exceptional character, these segregated tracts are parks in themselves, and should so be called.

But the identity of our five national parks in the farther West is unmistakable; and these would appear to 


\section{FOREST TREES AND FOREST SCENERY}

suggest neither forestry proper, nor landscape forestry, nor even landscape art. In them nature speaks for herself. The tasteful and well judged construction of roads and trails that shall be in harmony with the scenes through which they pass, or, better still, that shall be as unobtrusive as possible, is evidently a necessity if the parks are to be enjoyed by large numbers of people. In exceptional cases the ax may be needed for the very preservation of the forest. But the principal care should be to protect these forests from fire, defacement, and spoliation. For to us and future generations the parks stand, above all, as examples of the glory of our primeval forests.

The groves of big trees in the na168 


\section{ARTIFICTAL FORESTS OF EUROPE}

tional parks of Califormia, the geologic wonders of Yellowstone, and the specimens of arctic fauna still living among the matchless glaciers of Mount Rainier, are national possessions of great interest, for whose preservation not only Americans, but distinguished Europeans also, have pleaded. These, then, are ours for their own sakes; but most of our other national forest possessions will undoubtedly have to submit to further development and to the dictates of a sterner necessity. 



\section{NOTES}

Note 1, page 5. There are about fifty distinct species of oak indigenous to the United States.

Note 2, page 23. The bloom of the dogwood begins to wither and fall with the appearance of the leaves. In the illustration facing page $22 \mathrm{sev}$ eral leaves are seen among the bloom, but they belong to the bough of a neighboring tulip tree.

Note 3, page 47. The juniper berries are in reality transformed cones.

Note 4, page 52. The habit of the firs in early life is shown in the plate facing page 125.

Note 5, page 63. Curiously enough, the old English conception of a forest was chiefly that of a hunting ground, irrespective of the trees growing there. Consequently some forestis were very open stretches of ground.

Note 6, page 71. The red-winged blackbird lingers in the Southern States through the winter.

Note 7, page 163. German forestry - and, in a less degree, European forestry also - is indebted to Herr von Salisch for elaborating the idea that forest art can be united with practical, utilitarian forestry. His book on "Forest Esthetics," which fills a unique place in the literature of forestry, is an exposition of this interesting subject, based upon mature knowledge and experience. 
Note 8, page 163. To the reader who is not familiar with the origin of our forest reserves it may be of interest to know how they became established. By an act of Congress of March 3rd, 1891, the President was empowered to segregate from time to time, and for the benefit of the American people, forest areas situated within the limits of the public lands of the United States. In accordance with this act proclamations were issued by Presidents Cleveland, Harrison, and McKinley, reserving forest areas amounting thus far (September 1st, 1901) to $46,398,369$ acres, or approximately 72,500 square miles. There are, however, within these areas numerous bona fide holdings of private ownership, in which the owners are carrying on extensive cutting of timber.

The reserves have been placed under the authority of the Commissioner of the General Land Office, Department of the Interior, and are entrusted to the care of specially appointed superintendents, supervisors, and rangers. Some of these forest tracts are now undergoing a careful study by experts in forestry, with the aim of subjecting them to methods of treatment specially adapted to them, in order that they may yield both useful material and a constant revenue, without impairing the productive power or vitality of the forest. The objects will thereby be fulfilled for which these reserves were established. 


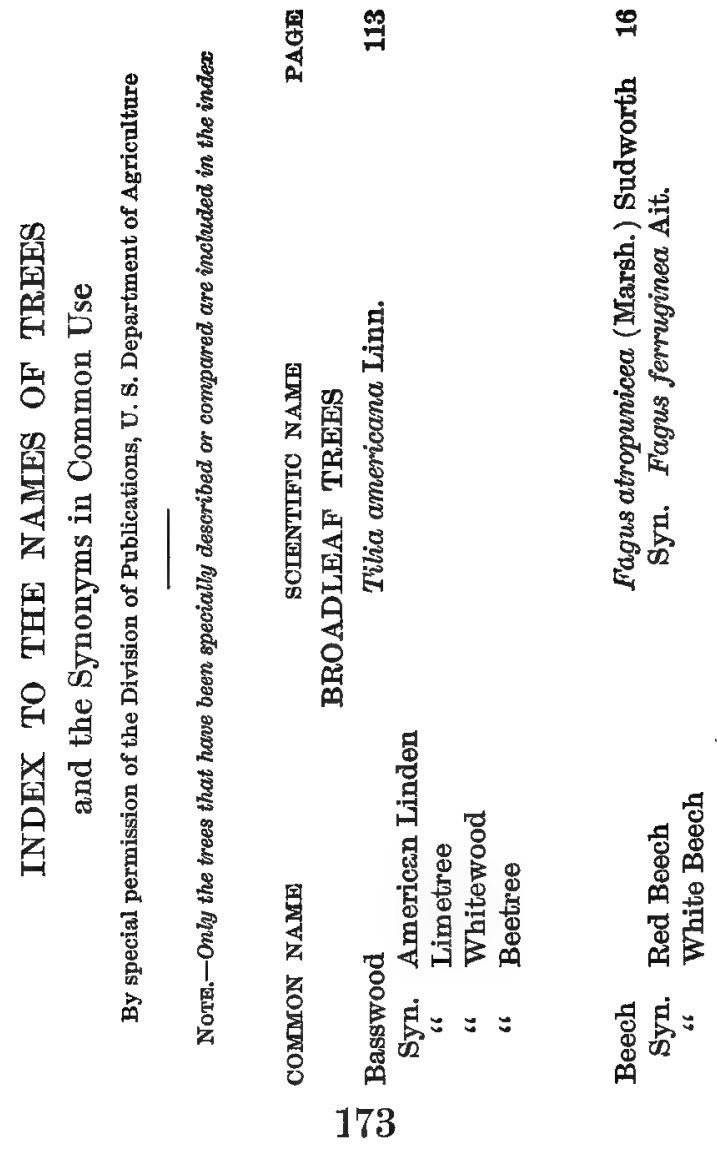



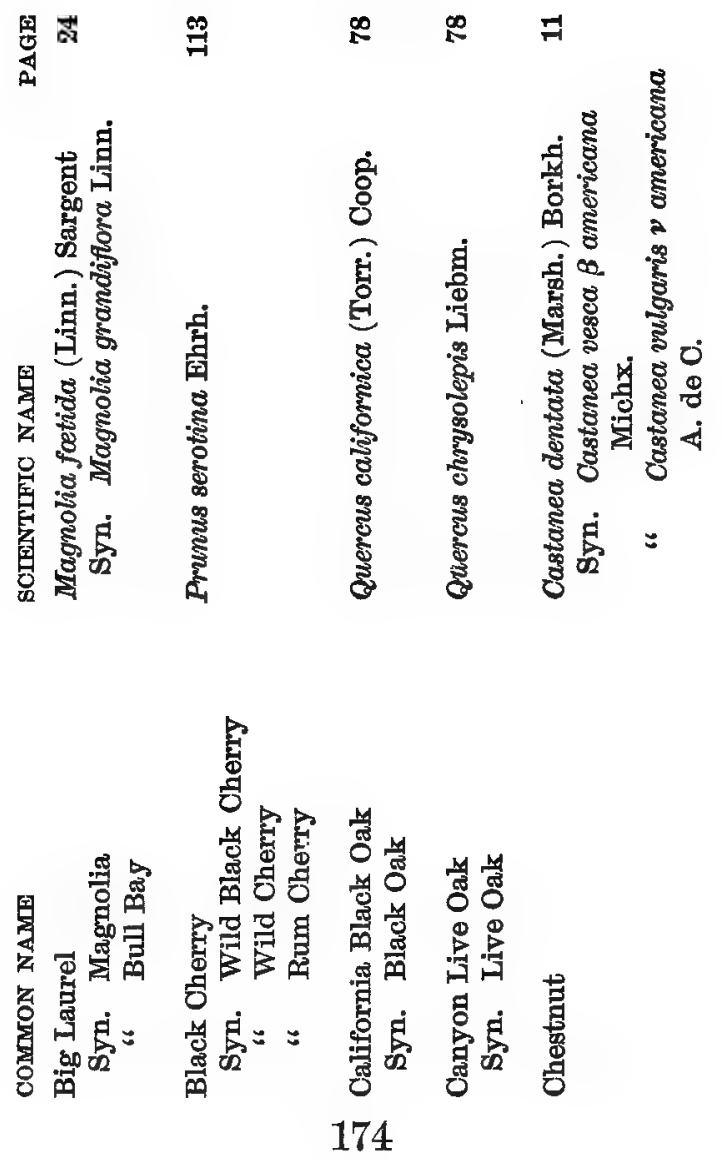

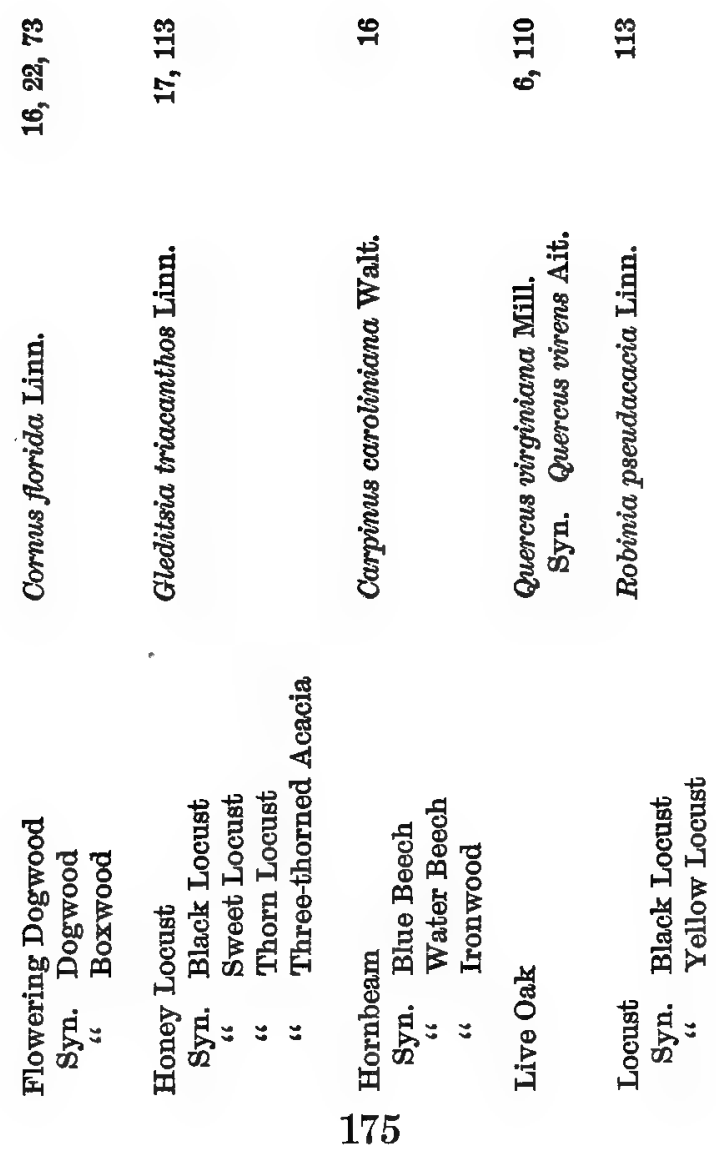

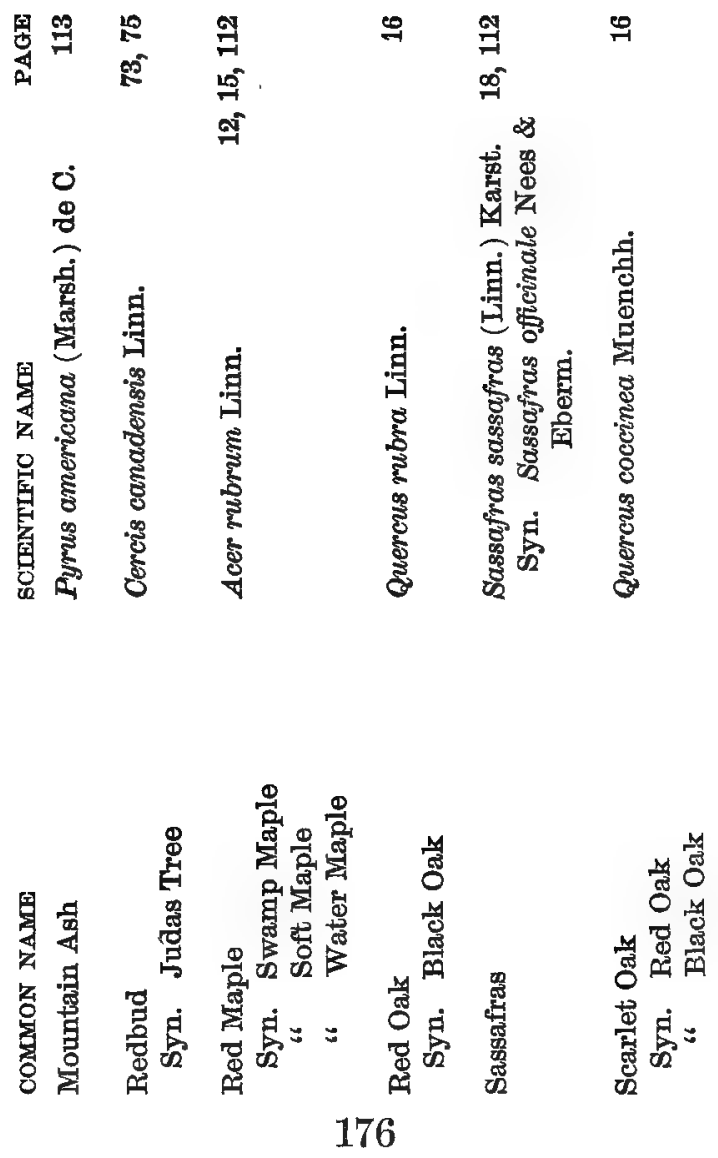

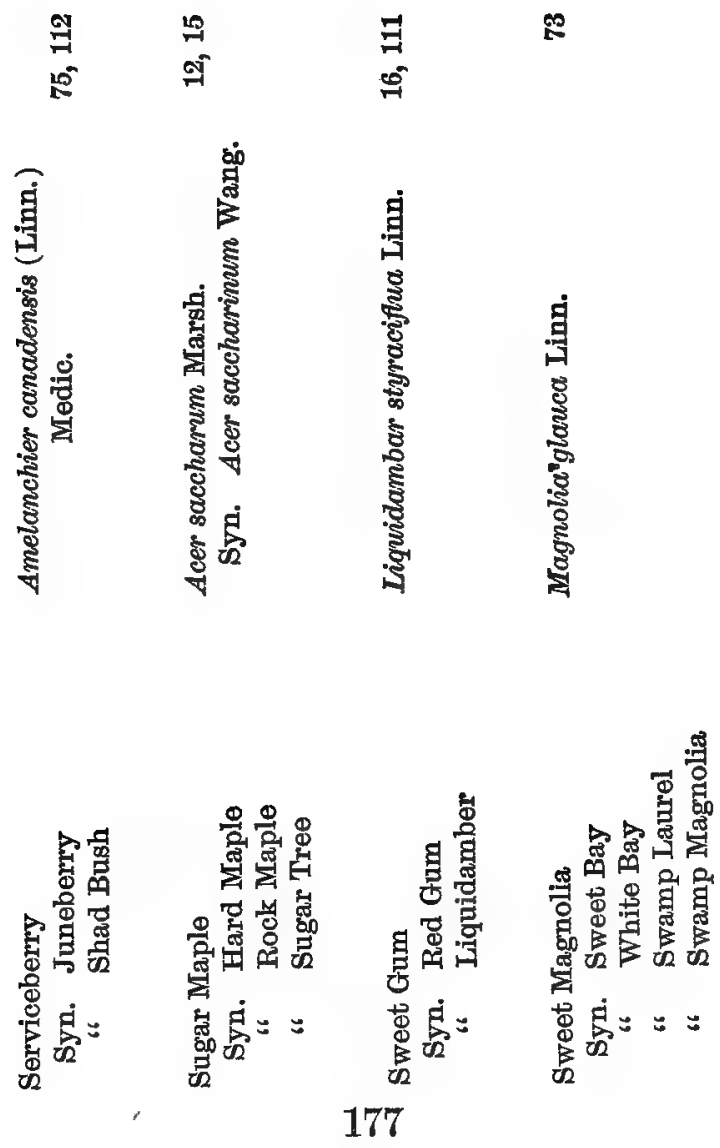
国 芯

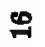

염

ตี

15
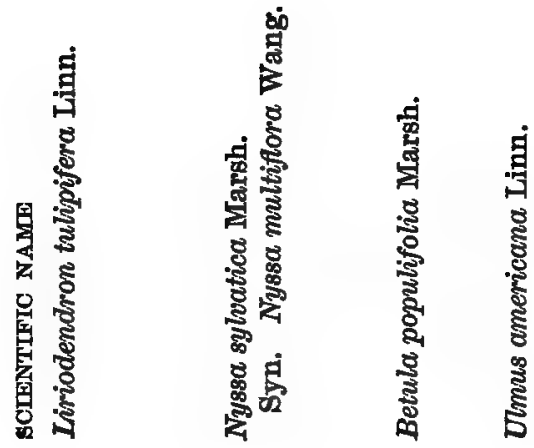

욜

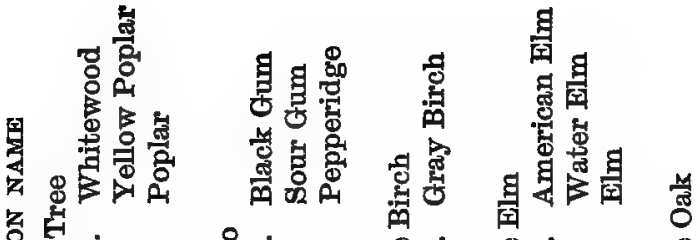

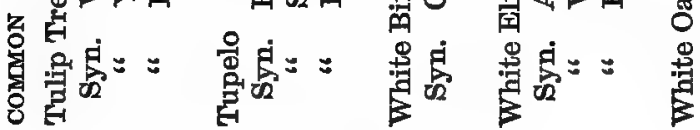
178 

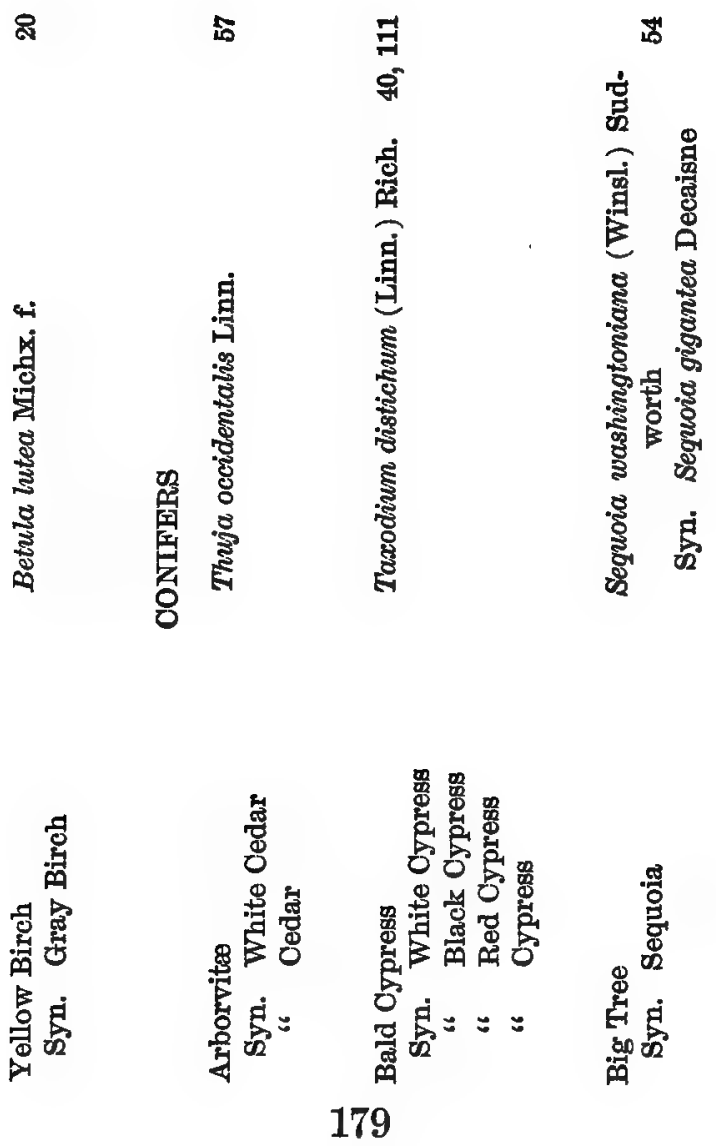

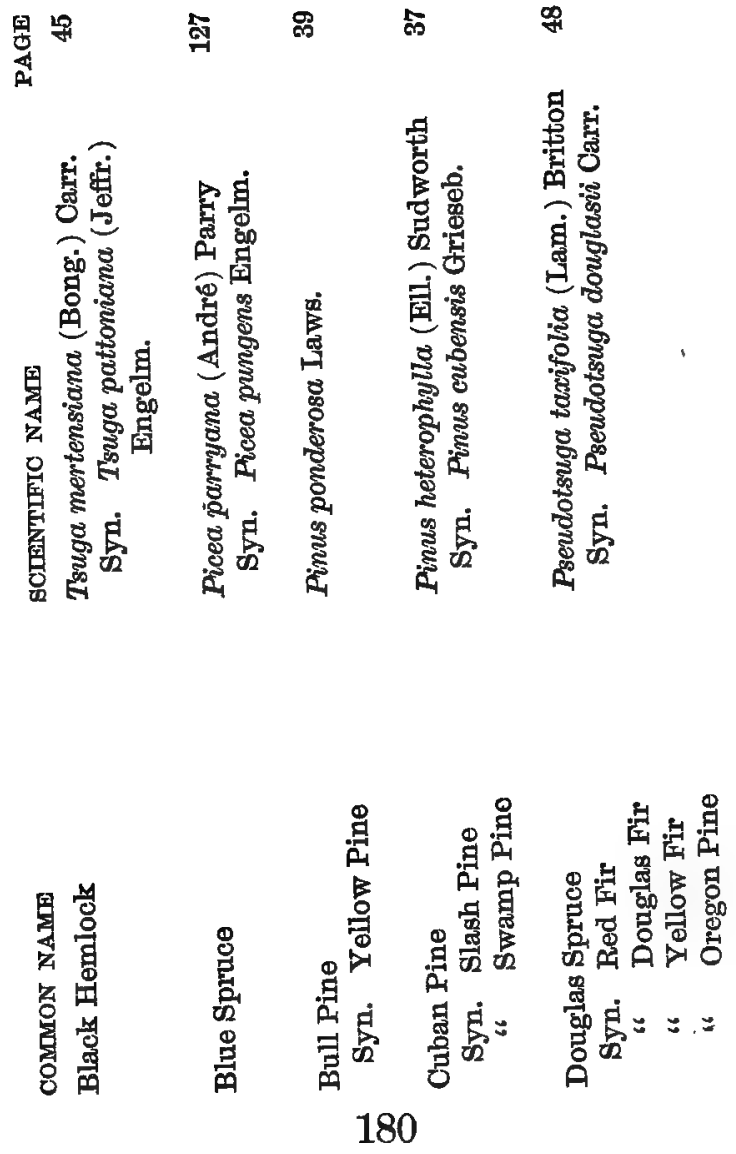

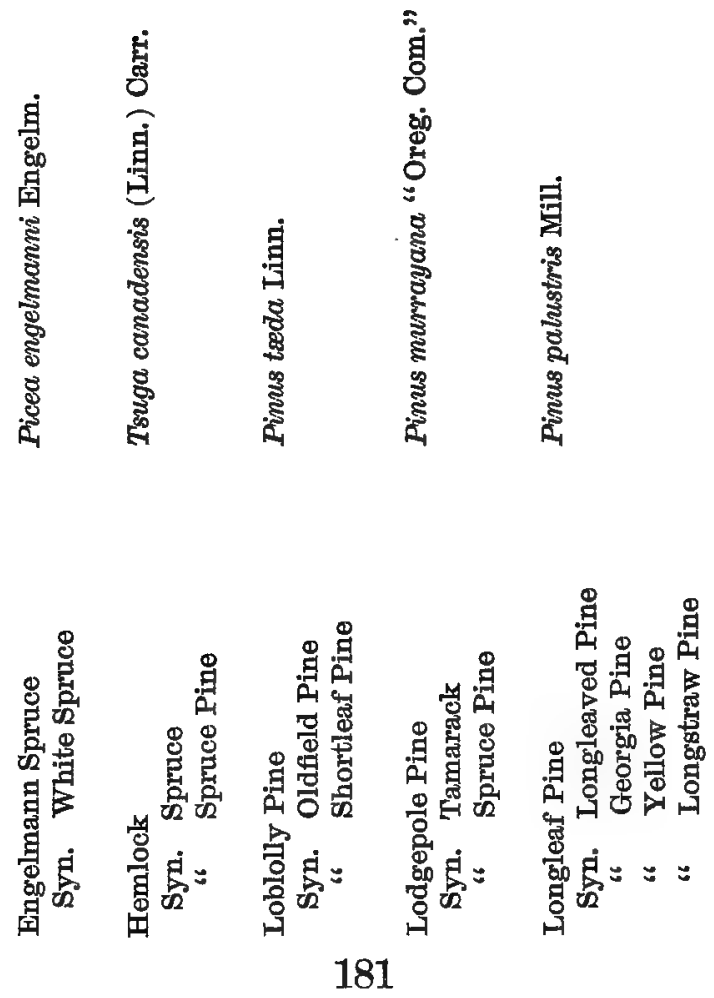

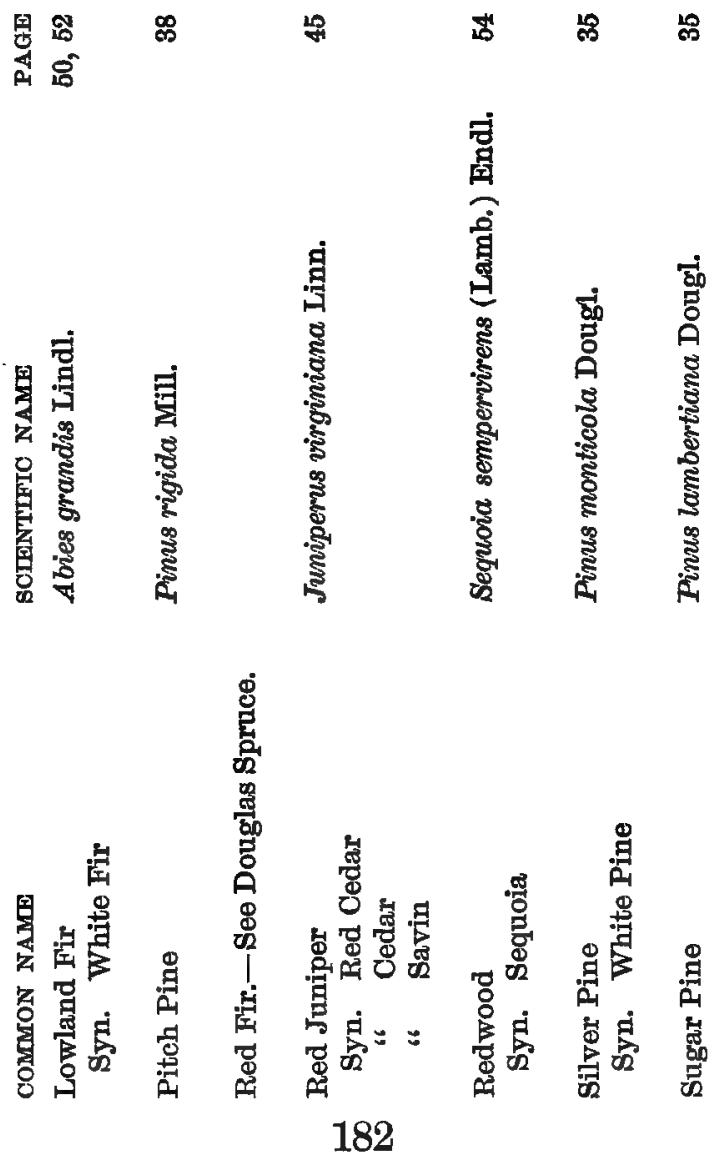

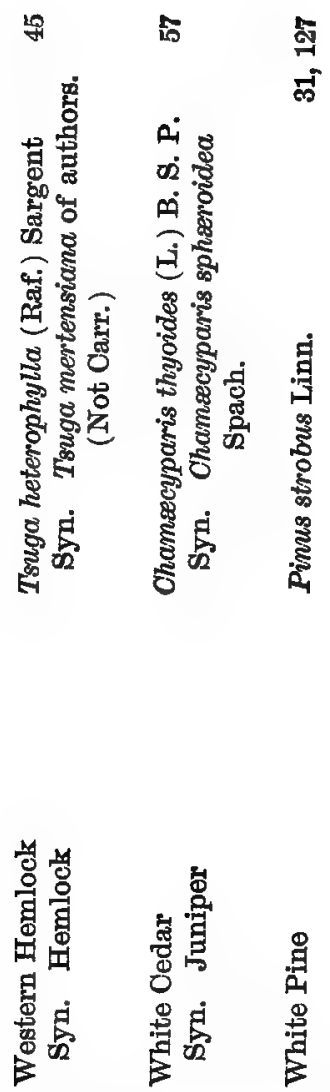

183 






